\title{
In situ imaging of bacterial membrane projections and associated protein
}

$$
\text { complexes using electron cryo-tomography }
$$

Mohammed Kaplan ${ }^{1}$, Georges Chreifi ${ }^{1}$, Lauren Ann Metskas ${ }^{1}$, Janine Liedtke ${ }^{2}$, Cecily R Wood ${ }^{3}$, Catherine M Oikonomou ${ }^{1}$, William J Nicolas ${ }^{1}$, Poorna Subramanian ${ }^{1}$, Lori A Zacharoff ${ }^{4}$, Yuhang Wang ${ }^{1}$, Yi-Wei Chang ${ }^{5}$, Morgan Beeby ${ }^{6}$, Megan Dobro ${ }^{7}$, Mark J McBride ${ }^{8}$, Ariane Briegel $^{2}$, Carrie Shaffer ${ }^{3,9,10}$, Grant J Jensen ${ }^{1,11,12}$

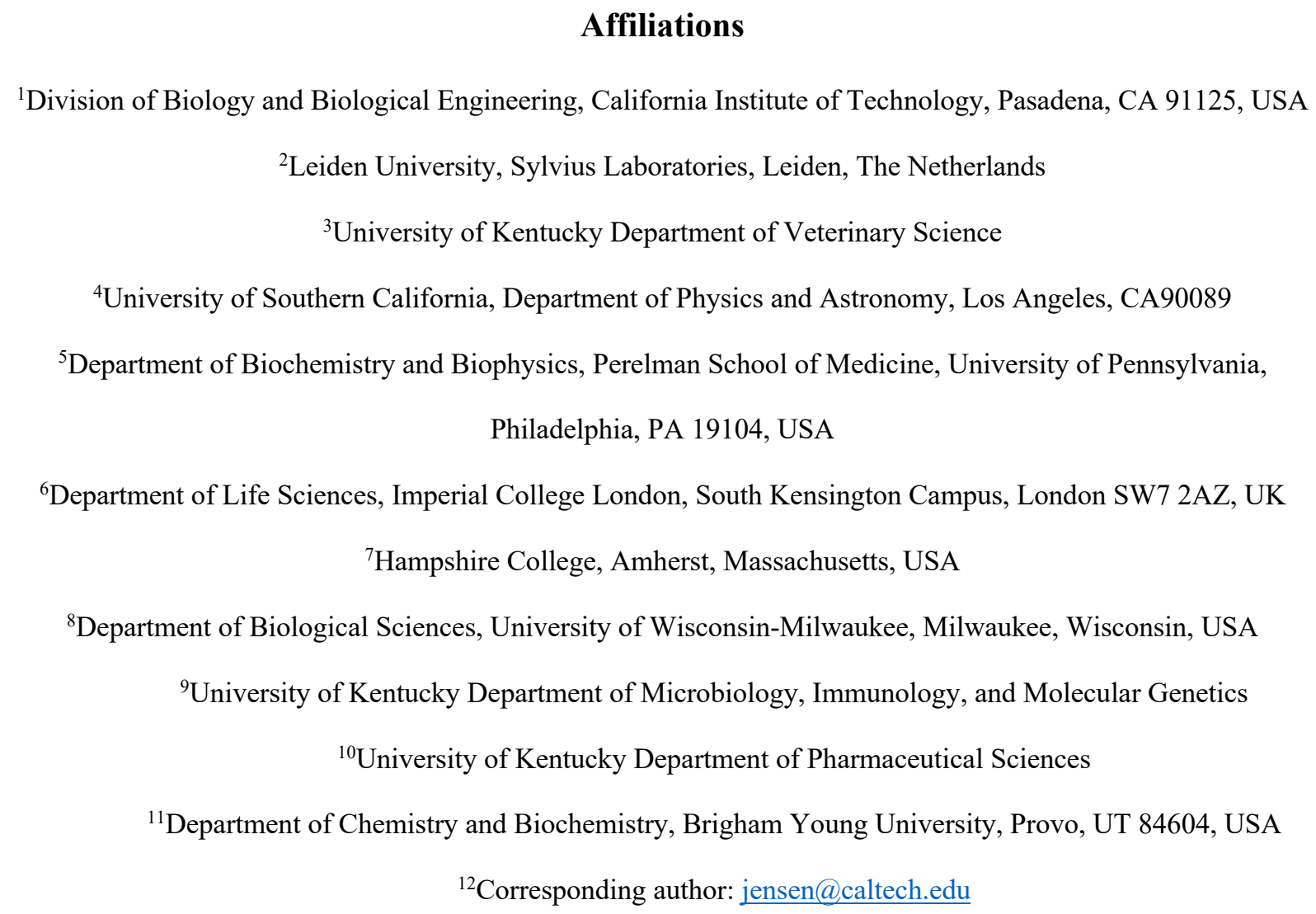




\section{Abstract}

27 The ability to produce membrane projections in the form of tubular membrane extensions (MEs)

28 and membrane vesicles (MVs) is a widespread phenomenon among bacteria. Despite this, our

29 knowledge of the ultrastructure of these extensions and their associated protein complexes remains

30 limited. Here, we surveyed the ultrastructure and formation of MEs and MVs, and their associated

31 protein complexes, in tens of thousands of electron cryo-tomograms of $\sim 90$ bacterial species that

32 we have collected for various projects over the past 15 years (Jensen lab database), in addition to

33 data generated in the Briegel lab. We identified MEs and MVs in 13 species and classified several

34 major ultrastructures: 1) tubes with a uniform diameter (with or without an internal scaffold), 2)

35 tubes with irregular diameter, 3) tubes with a vesicular dilation at their tip, 4) pearling tubes, 5)

36 connected chains of vesicles (with or without neck-like connectors), 6) budding vesicles and

37 nanopods. We also identified several protein complexes associated with these MEs and MVs

38 which were distributed either randomly or exclusively at the tip. These complexes include a

39 secretin-like structure and a novel crown-shaped structure observed primarily in vesicles from

40 lysed cells. In total, this work helps to characterize the diversity of bacterial membrane projections

41 and lays the groundwork for future research in this field. 


\section{Introduction}

50 Membrane extensions and vesicles (henceforth referred to as MEs and MVs) have been described

51 in many types of bacteria. They are best characterized in diderms, where they stem mainly from

52 the outer membrane (OM; we thus refer to OMEs and OMVs) and perform a variety of functions

53 [1-4]. For example, the OMEs of Shewanella oneidensis (aka nanowires) are involved in

54 extracellular electron transfer [5,6]. The OM tubes of Myxococcus xanthus are involved in the

55 intra-species transfer of periplasmic and OM-associated material between different cells that is

56 essential for the complex social behavior of this species [7-9]. The OMVs of Vibrio cholerae act

57 as a defense mechanism, helping the bacterium circumvent phage infection [10]. A marine

58 Flavobacterium affiliated with the genus Formosa (strain Hel3_A1_48) extrudes membrane tubes

59 and vesicles that contain the type IX secretion system and digestive enzymes [11]. OMVs often

60 function in pathogenesis. The OM blebs and vesicles of Flavobacterium psychrophilum have

61 proteolytic activities that help release nutrients from the environment and impede the host immune

62 system [12]. The OMVs of Francisella novicida contain virulence factors, suggesting they are

63 involved in pathogenesis [13]. Similarly, the virulence of Flavobacterium columnare is associated

64 with the secretion of OMVs [14], and membrane tubes and secreted vesicles have been observed

65 in other, human pathogens like Helicobacter pylori and Vibrio vulnificus $[15,16]$.

67 MEs and MVs are also produced by monoderm bacteria and archaea. MVs stemming from the

68 cytoplasmic membrane of Gram-positive bacteria have been reported to encapsulate DNA (see

69 Ref. [17] and references therein.) Membrane nanotubes were recently discovered in the Gram-

70 positive Bacillus subtilis, as well as the Gram-negative Escherichia coli. These nanotubes were

71 found to connect two different bacterial cells and are involved in the transfer of cytoplasmic 
72 material between bacterial cells of the same and different species, and even to eukaryotic cells

$73[18-24]$.

74

75 The structures of MEs and MVs are as varied as their functions. While S. oneidensis nanowires

76 are chains of interconnected outer membrane vesicles with variable diameter and decorated with

77 cytochromes [6], OM tubes of $H$. pylori have a fixed diameter of $\sim 40 \mathrm{~nm}$ and are characterized by

78 an inner scaffold and lateral ports [15]. V. vulnificus produces tubes from which vesicles ultimately

79 pinch off by biopearling, forming a regular concentric pattern surrounding the cell [16]. Cells with

80 an external surface layer (S-layer) can produce structures known as "nanopods," which consist of

81 membrane vesicles inside a sheath of S-layer. These have been reported in the soil-residing

82 bacterium Delftia sp. Cs1-4 [25] and archaea of the order Thermococcales [26]. Finally, some

83 diderms produce DNA-containing MVs consisting of both inner and outer membranes (see Ref.

$84[4]$ and references therein).

86 Different models have been proposed for how MEs and MVs form. In diderms, membrane

87 blebbing may occur due to changes in the periplasmic turgor pressure, lipopolysaccharide

88 repulsion or alterations in the contacts between the OM and the peptidoglycan cell wall [4]. Chains

89 of interconnected vesicles are often observed, either as a result of direct vesicular budding from

90 the OM or due to biopearling of membrane tubes $[6,11]$. Formation of tubes is thought to be a

91 stabilizing factor as it results in smaller vesicles, with tubes pearling into distal chains of vesicles

92 that eventually disconnect [27]. Other extensions may be formed by dedicated machinery.

93 Interestingly, nanotubes involved in cytoplasmic exchange have been reported to be dependent on

94 a conserved set of proteins involved in assembly of the flagellar motor known as the type III 
95 secretion system core complex (CORE): FliP/O/Q/R and FlhA/B [18,24]. Recently, it was also

96 shown that the formation of bacterial nanotubes significantly increases under stress conditions or

97 in dying cells, caused by biophysical forces resulting from the action of the cell wall hydrolases

98 LytE and LytF [28].

99

100 Structural studies of MEs and MVs have relied mainly on scanning electron microscopy (SEM),

101 conventional transmission electron microscopy (TEM), and light (fluorescence) microscopy.

102 While these methods have significantly advanced our understanding, they are limited in terms of

103 the information they can provide. For instance, in SEM and conventional TEM, sample preparation

104 such as fixation, dehydration, and staining disrupt membrane ultrastructure. While light

105 microscopy can reveal important information about the dynamics and timescales on which MEs

106 and MVs form (e.g. [29]), no ultrastructural details can be resolved; MEs and MVs of different

107 morphology appear identical. Currently, only electron cryo-tomography (cryo-ET) allows

108 visualization of structures in a near-native state inside intact (frozen-hydrated) cells with

109 macromolecular $(\sim 5 \mathrm{~nm})$ resolution. This method has already been invaluable in revealing the

110 structures of several membrane extensions, including S. oneidensis nanowires [6], H. pylori

111 nanotubes [15], D. acidovorans nanopods [25], V. vulnificus OMV chains [16], and more recently

112 cell-cell bridges in the archaeon Haloferax volcanii [30].

114 To understand what membrane extensions exist in bacterial cells and how they might form, we

115 undertook a survey of $\sim 90$ bacterial species, drawing on a database of tens of thousands of electron

116 cryo-tomograms of intact cells collected by our group for various projects over the past 15 years

117 [31,32], in addition to data generated in the Briegel lab. Our survey revealed membrane projections 
118 in 13 bacterial species. These projections took various forms: 1) tubes with a uniform diameter 119 and with an internal scaffold, 2) tubes with a uniform diameter and without a clear internal scaffold,

120 3) tubes with a vesicular dilation at their tip (teardrop-like extensions), 4) tubes with irregular

121 diameter or pearling tubes, 5) interconnected chains of vesicles with uniform neck-like connectors,

122 6) budding or detached OMVs, and 7) nanopods. We also identified protein complexes associated

123 with MEs and MVs in these species. These complexes were either randomly distributed on the

124 MEs and MVs or exhibited a preferred localization at their tip.

125

126

127

128

129

130

131

132

133

134

135

136

137

138 


\section{Results:}

142 We examined tens of thousands of electron cryo-tomograms of $\sim 90$ bacterial species collected in

143 the Jensen lab for various projects over the past 15 years together with tomograms collected in the

144 Briegel lab. Most cells were intact, but some had naturally lysed. Note that we make this

145 classification based on the cells' appearance in tomograms; intact cells have an unbroken cell

146 envelope, uniform periplasmic width, and consistently dense cytoplasm. In addition to cryo-

147 tomograms of cells, this dataset also included naturally-shed vesicles purified from $S$ oneidensis.

148 In all, we identified OMEs and OMVs in 13 bacterial species (summarized in Table S1).

\section{I- The diverse forms of bacterial membrane structures}

151 Based on their features, we classified membrane projections into the following categories: 1)

152 tubular extensions with a uniform diameter and with an internal scaffold (Fig. 1 a \& b); 2) tubular

153 extensions with a uniform diameter and without a clear internal scaffold (Fig. $1 \mathrm{c}-\mathrm{g}$ ); 3) tubular

154 extensions with a vesicular dilation at the tip (a teardrop-like structure) and irregular dark densities

155 inside (Fig. 1h); 4) tubular extensions with irregular diameter or pearling tubes (Fig. 2 a-g); 5)

156 interconnected chains of vesicles with uniform neck-like connectors (Fig. 2 h \& i); 6) budding or

157 detached vesicles: budding vesicles were still attached to the membrane, while detached vesicles

158 were observed near a cell and could have budded directly or from a tube that pearled (Fig. 3 a-d);

159 7) nanopods: tubes of S-layer containing OMVs (Fig. 3 e-i). See Table S1 for a summary of these 160 observations.

162 Scaffolded membrane tubes were observed only in H. pylori and had a uniform diameter of $40 \mathrm{~nm}$.

163 The H. pylori strain imaged $\left(f l i P^{*}\right)$ contains a naturally-occurring point mutation that disrupts the 
164 function of FliP, the platform upon which other CORE proteins assemble [33-35]. In addition, the dataset contained other mutants in this $f l i P^{*}$ background including additional CORE proteins $(\Delta f i O$ and $\Delta f l i Q)$, flagellar basal body proteins $(\Delta f l i M$ and $\Delta f l i G)$, and the tyrosine kinase required for

167 expression of the class II flagellar genes $(\Delta f l g S)[36]$ (Figs. 1 a-b and 4). This suggests that the $H$. pylori membrane tubes are unrelated to the CORE-dependent nanotubes that mediate cytoplasmic

169 exchange in B. subtilis and other species [18,24].

171 Previously, H. pylori tubes were described as forming in the presence of eukaryotic host cells [15].

172 Here, however, we observed tubes on H. pylori grown on agar plates in the absence of eukaryotic

173 cells, suggesting that they also form in the absence of host cells. We observed some differences,

174 though, from the tubes formed in the presence of host cells: the tube ends were closed, no clear

175 lateral ports were seen, and the tubes were usually straight. While some of these tubes extended

176 more than $0.5 \mu \mathrm{m}$, we never observed pearling. However, in some tubes, the internal scaffold did

177 not extend all the way to the tip, and its absence caused the tube to dilate (from $40 \mathrm{~nm}$ in the

178 presence of the scaffold to $66 \mathrm{~nm}$ in its absence, see Fig. 4f). In some cases we also observed tubes 179 stemming from vesicles resulting from cell lysis (Figs. 4f and S1). extracted from sugar beet roots, in addition to tubes with irregular diameter and OMVs, tubular 183 extensions with a uniform diameter and a vesicular dilation (teardrop-like structure) were observed 184 stemming from the sides of the cell (Fig. 1h). Interestingly, irregular dark densities were observed 185 inside these teardrop-like extensions (Fig. 1h). Chains of vesicles connected by neck-like bridges 
187

$\sim 14 \mathrm{~nm}$ in length and $\sim 8 \mathrm{~nm}$ in width. Where chains were seen attached to the outer membrane, a neck-like connection was present at the budding site (Fig. 2h). Vesicles in each chain were of a uniform size, usually 35-40 nm wide (e.g. Fig. 2i), but occasionally larger (e.g. Fig. 2h).

When both tubes and vesicles were observed in the same species, the tubes generally had a more uniform diameter than the vesicles, which were of variable sizes and often had larger diameters than the tubes (Figs. S2 \& S3). In addition, when a tube pearled into vesicles, there was no clear correlation between the length of the tube and the initiation point of pearling, with some tubes extending for many micrometers without pearling while other, shorter tubes were in the process of forming vesicles (Movies S1, S2, S3 and Fig. 2e). While most pearling was seen at the tips of tubes, pearling occasionally occurred simultaneously at both proximal and distal ends of the same tube (Movie S3). With one exception, pearling was seen in all species with tubes of uniform diameter and no internal scaffold. The exception was lysed Pseudoalteromonas luteoviolacea, which had narrow tubes only $20 \mathrm{~nm}$ in diameter (Fig. 1g). Some lysed P. luteoviolacea contained wider, pearling tubes (Fig. 2c). Interestingly, the tubes of various M. xanthus strains (see Materials and Methods) and $P$. luteoviolacea could bifurcate into branches, each of which had a uniform diameter similar to that of the main branch (Movie S4 and Fig. 1d and Fig. S4).

In C. crescentus tomograms, we identified structures very similar to the "nanopod" extensions previously reported in D. acidovorans [25]. These structures consist of a tube made of the S-layer encasing equally-spaced OMVs (Fig. 3 e-h and Movie S5). The diameter of the S-layer tubes was $\sim 45 \mathrm{~nm}$ and vesicles exhibited diameters ranging from $\sim 13-25 \mathrm{~nm}$. The nanopods were seen either detached from the cell (Fig. $3 \mathrm{e}-\mathrm{g}$ ), or budding from the pole of C. crescentus (Fig. 3h). 


\section{II- Protein complexes associated with membrane structures.}

211 Next, we examined protein complexes associated with OMEs and OMVs that we could identify in

212 our cryo-tomograms. These complexes fell into three categories: 1) randomly-located complexes

213 found on OMEs, OMVs and cells; 2) randomly-located complexes observed only on OMEs and

214 OMVs, and 3) complexes exclusively located at the tip of OMEs/OMVs.

216 In the first category, we observed what appeared to be the OM-associated portion of the empty

217 basal body of the type IVa pilus (T4aP) machinery in OMEs of $M$. xanthus. These complexes, 218 which were also found in the OM of intact cells, did not exhibit a preferred localization within the 219 tube (Fig. 5a \& b).

221 The second category of protein complexes, observed only on MEs and not on cells, contained two 222 structures. The first was a trapezoidal structure observed on purified OMVs of $S$. oneidensis. The 223 structure was $\sim 11 \mathrm{~nm}$ wide at its base at the membrane and was seen sometimes on the outside 224 (Fig. 5c) and sometimes the inside of vesicles (Fig. 5 d). The second structure was a large crown225 like complex. We first observed these complexes on the outer surface of membrane vesicles 226 associated with lysed M. xanthus cells (Fig. 6a). Occasionally, they were also present on what 227 appeared to be the inner leaflet of the inner membrane of lysed cells (Fig. 6b). The exact topology 228 is difficult to determine, however, since the arrangement of inner and outer membranes can be 229 confounded by cell lysis. The structure of this complex was consistent enough to produce a 230 subtomogram average from nine examples, improving the signal-to-noise ratio and revealing 231 greater detail (Fig. 6c). These crown-like complexes are $\sim 40 \mathrm{~nm}$ tall with a concave top and a base $232 \sim 35 \mathrm{~nm}$ wide at the membrane (Fig. 6c). No such complexes were seen on OMEs and OMVs 
233 associated with intact $M$. xanthus cells. We identified a morphologically similar crown-like

234 complex on the outside of some tubes and vesicles purified from S. oneidensis (Fig. 6d-f). However,

235 this complex was smaller, $\sim 15 \mathrm{~nm}$ tall and $\sim 20 \mathrm{~nm}$ wide at its base. As these were purified

236 OMEs/OMVs, we cannot know whether they stemmed from lysed or intact cells. Interestingly, we

237 found a similar large crown-like structure associated with lysed cells of two other species in which

238 we did not identify MEs, namely Pseudomonas flexibilis and Pseudomonas aeruginosa (Fig. 6g-j

$239 \&$ S5).

240

241 In the third category, we observed a secretin-like complex in many tubes and vesicles of $F$.

242 johnsoniae. In tubes attached to the cell, the complex was always located at the distal tip (Figs. 7

$243 \&$ S6 and Movie S6). From 35 membrane tubes seen attached to cells, we identified a secretin-like

244 complex at the tip of 25 of them $(\sim 70 \%)$. In OMEs disconnected from the cell, the secretin-like

245 complex was always located at one end (Fig. 7b \& e). In total, in 198 tomograms we identified 88

246 secretin-like particles, none of which were located in the middle of a tube. As the MEs are less

247 crowded than cellular periplasm and usually thinner than intact cells, we could clearly distinguish

248 an extracellular density and three periplasmic densities in side views (red and purple arrows,

249 respectively, in Fig. 7a). Top views showed a plug in the center of the upper part of the complex

250 (yellow arrows in Fig. $7 \mathrm{~g} \& \mathrm{~h}$ ). Subtomogram averaging revealed details of the complex, including

251 the plug and a distinct lower periplasmic ring (Fig. 7i \& j \& S7). While the upper two periplasmic

252 rings were clearly distinguishable in many of the individual particles (e.g. Fig. 7a), they did not

253 resolve as individual densities in the subtomogram average (Fig. 7i). The extracellular density was

254 not resolved at all in the average, suggesting flexibility in this part. 
256 Previous studies showed that a species which belongs to the same phylum as $F$. johnsoniae, namely

257 Cytophaga hutchinsonii, uses a putative T2SS to degrade cellulose [37]. Since F. johnsoniae also

258 degrades polysaccharides and other polymers, we BLASTed the sequence of the well-

259 characterized $V$. cholerae T2SS secretin protein, GspD (UniProt ID P45779), against the genome

260 of F. johnsoniae and found a hit, GspD-like T2SS secretin protein (A5FMB4), with an e-value of

$261 \mathrm{e}^{-9}$. This result and the general morphological similarity of this secretin to the published structure

262 of the T2SS [38] suggested that the complex we observed might be the secretin of a T2SS. We

263 therefore compared our subtomogram average with the only available in situ structure of a T2SS,

264 a recent subtomogram average of the Legionella pneumophila T2SS [38] (Fig. 7i-1). The two

265 structures were generally similar in length and both had a plug in the upper part of the complex.

266 However, we also observed differences between the two structures. In L. pneumophila, the widest

267 part of the secretin $(15 \mathrm{~nm})$ is located near the plug close to the OM, and the lower end of the

268 complex is narrower $(12 \mathrm{~nm})$. In $F$. johnsoniae, this topology is reversed, with the narrowest part

269 near the plug and OM (Fig. 7i-1). Additionally, the lowest domain of the L. pneumophila secretin

270 did not resolve into a distinct ring as we saw in $F$. johnsoniae and no extracellular density was

271 observed in L. pneumophila, either in the subtomogram average or single particles [38]. 


\section{Discussion:}

280 Our results highlight the diversity of MEs and MVs structures that bacteria can form even within

281 a single species (Fig. 8). For example, we saw two types of membrane tubes in lysed $P$.

282 luteoviolacea cells: one narrower with a uniform diameter of $20 \mathrm{~nm}$ which did not pearl into

283 vesicles, and one wider with a variable diameter that did pearl into vesicles (Fig. 1g and Fig. 2c),

284 a distinction which suggests that these extensions play different roles. Similarly, interspecies

285 differences likely reflect different functions. For instance, the tubes of M. xanthus were on average

286 longer, more abundant and more branched than the MEs of other species (Movies S1 \& S4), which

287 is likely related to their role in communication between cells of this highly social species. However,

288 one interesting observation in all the species we investigated here is that there was no clear

289 distinctive molecular machine at the base of the membrane projections, raising the question of

290 what drives their formation. This observation is consistent with a recent study which showed that

291 liquid-like assemblies of proteins in membranes can lead to the formation of tubular extensions

292 without the need for solid scaffolds [39].

293

294 The scaffolded uniform tubes of $H$. pylori that we observed were formed in samples not incubated

295 with eukaryotic cells, indicating that they can also form in their absence. However, the tubes we

296 found had closed ends and no clear lateral ports, while some of the previously-reported tubes

297 (formed in the presence of eukaryotic host cells) had open ends and prominent ports [15]. It is

298 possible that such features are formed only when $H$. pylori are in the vicinity of host cells. We also

299 show that the tubes of $H$. pylori are CORE-independent, indicating that they are different from the

300 CORE-dependent nanotubes described in other species. 
302 A recent study showed that the formation of bacterial tubes significantly increases when cells are

303 stressed or dying [28]. Consistent with this, in our cryo-tomograms we saw many MEs and MVs

304 associated with lysed cells (such as in H. pylori, H. hepaticus, and P. luteoviolacea). We also saw

305 tubes and vesicles stemming from intact cells. Given the nature of cryo-ET snapshots, we cannot

306 tell whether a cell that appears intact is stressed, nor can we know whether MEs/MVs formed

307 before or after a cell lysed. One observation which might be related to this issue comes from $F$.

308 johnsoniae where tubes with regular diameters were seen stemming mainly from cells with a

309 noticeably wavy OM (45 examples), while pearling tubes and OMVs stemmed primarily from

310 cells with a smooth outer membrane ( $>100$ examples). Compare, for example, the cells in Figures

311 1e and S6 and Movies S2 and S6 (wavy OM) to those in Figures 3d, 7a and f (smooth OM).

313 In C. crescentus, we observed for the first time "nanopods," a structure previously reported in $D$.

314 acidovorans [25]. Both of these species are diderms with an S-layer, suggesting that nanopods

315 may be a general form for OMVs in bacteria with this type of cell envelope. Nanopods were

316 proposed to help disperse OMVs in the partially hydrated environment of the soil where $D$.

317 acidovorans lives; it will be interesting to study their function in aquatic C. crescentus.

319 Examining protein complexes associated with OMEs and OMVs, some seemed to reflect a 320 continuation of the same complexes found on the membrane from which the extensions stemmed,

321 such as the T4aP basal body in M. xanthus [40]. Others, however, were only observed on MEs and 322 not on cells. This could be because the complexes are related to the formation of the MEs, or it 323 might simply reflect the fact that these extensions are generally thinner and less crowded than the 324 bacterial periplasm, making the complexes easier to see in cryo-tomograms. Interestingly, the 
crown-like complex we observed in M.xanthus, $P$. aeruginosa and P. flexibilis was exclusively associated with the membranes of lysed cells; we never observed it on OMEs and OMVs stemming

327 from intact cells in M. xanthus. We observed a morphologically-similar crown-like structure with

328 different dimensions in purified naturally-shed MEs/MVs of S. oneidensis, where we cannot know

329 whether they arose from intact or lysed cells. The crown-like structures are remarkably large and

330 their function remains a mystery. Due to the disruption of membranes in lysed cells, the topology

331 of these complexes is difficult to unravel. However, these structures share a morphological

332 similarity to a membrane-associated dome protein complex recently described on the limiting

333 membrane of the lamellar bodies inside alveolar cells [41].

335 Similarly, regarding the different, trapezoidal structure in S. oneidensis, the fact that it was seen 336 on both the outside and inside of purified MVs suggests that some of the purified vesicles adopted 337 an inside-out orientation during purification (a documented phenomenon [42]). Interestingly, the 338 overall architecture and dimensions of this trapezoidal structure are reminiscent of those of a 339 recently-solved structure of the E. coli polysaccharide co-polymerase WzzB [43]. We hope future 340 investigation by methods like mass spectrometry will characterize these novel ME/MV-associated 341 protein complexes.

343 In $F$. johnsoniae, we observed secretin-like particles at the tip of $\sim 70 \%$ of tubes stemming from

344 the OM. This strong spatial correlation suggests a role for the secretin-like complex in the 345 formation of MEs in this species. Based on homology, the GspD-like T2SS secretin is a strong 346 candidate for the complex. Interestingly, though, we did not identify any secretin-like (or full 347 T2SS-like) particles in the main cell envelope of $F$. johnsoniae cells. While we could have missed 
348 them in the denser periplasm compared to the less-crowded OMEs and OMVs, it is possible that

349 the structures are specifically associated with the formation of OMEs in this species. As these MEs

350 stem only from the OM, there is no IM- embedded energy source for the complex, suggesting that

351 they are not functional secretion systems and raising the question of what function they may serve.

352 It is possible that the OMVs and OMEs form to dispense of the secretin.

354 These complexes also indicate that MEs/MVs may provide an ideal system to investigate 355 membrane-embedded structures in their native environment at higher resolution. For example, it 356 remains unclear how secretins of various secretion systems are situated within the outer membrane.

357 All high-resolution structures were detergent solubilized, and most in situ structures have low 358 resolution due to cell thickness [44]. Purifying $F$. johnsoniae OMVs and performing high359 resolution subtomogram averaging on the secretin-like complex might shed light on this question.

361 Early in the history of life, lipid vesicles and elementary protocells likely experienced destabilizing 362 conditions such as repeated cycles of dehydration and rehydration [45]. The binding of prebiotic 363 amino acids to lipid vesicles can help stabilize them in such conditions [46] and it is conceivable 364 that with billions of years of evolution, variations of these stabilized lipid structures acquired roles 365 that conferred fitness advantages on bacterial species in various environments. Today, the ability 366 of bacteria to extend their membranes to form tubes or vesicles is a widespread phenomenon with 367 many important biological functions. We hope that the structural classification we present here 368 will serve as a helpful reference for future studies in this growing field. 


\section{References:}

372

373

374

375

376

377

378

379

380

381

382

383

384

385

386

1. Schwechheimer C, Kuehn MJ. Outer-membrane vesicles from Gram-negative bacteria: biogenesis and functions. Nature Reviews Microbiology. 2015;13: 605-619. doi:10.1038/nrmicro3525

2. Jan AT. Outer Membrane Vesicles (OMVs) of Gram-negative Bacteria: A Perspective Update. Frontiers in Microbiology. 2017;8. doi:10.3389/fmicb.2017.01053

3. D’Souza G, Shitut S, Preussger D, Yousif G, Waschina S, Kost C. Ecology and evolution of metabolic cross-feeding interactions in bacteria. Natural Product Reports. 2018;35: 455488. doi:10.1039/C8NP00009C

4. Toyofuku M, Nomura N, Eberl L. Types and origins of bacterial membrane vesicles. Nature Reviews Microbiology. 2019;17: 13-24. doi:10.1038/s41579-018-0112-2

5. Pirbadian S, Barchinger SE, Leung KM, Byun HS, Jangir Y, Bouhenni RA, et al. Shewanella oneidensis MR-1 nanowires are outer membrane and periplasmic extensions of the extracellular electron transport components. Proceedings of the National Academy of Sciences. 2014;111: 12883-12888. doi:10.1073/pnas.1410551111

6. Subramanian P, Pirbadian S, El-Naggar MY, Jensen GJ. Ultrastructure of Shewanella oneidensis MR-1 nanowires revealed by electron cryotomography. Proceedings of the National Academy of Sciences. 2018;115: E3246-E3255. doi:10.1073/pnas.1718810115

7. Ducret A, Fleuchot B, Bergam P, Mignot T. Direct live imaging of cell-cell protein transfer by transient outer membrane fusion in Myxococcus xanthus. eLife. 2013;2. doi:10.7554/eLife.00868

8. Wei X, Vassallo CN, Pathak DT, Wall D. Myxobacteria Produce Outer MembraneEnclosed Tubes in Unstructured Environments. Journal of Bacteriology. 2014;196: 18071814. doi:10.1128/JB.00850-13

9. Remis JP, Wei D, Gorur A, Zemla M, Haraga J, Allen S, et al. Bacterial social networks: structure and composition of Myxococcus xanthus outer membrane vesicle chains: Membrane vesicle chains and membrane network of M. xanthus. Environmental Microbiology. 2014;16: 598-610. doi:10.1111/1462-2920.12187

10. Reyes-Robles T, Dillard RS, Cairns LS, Silva-Valenzuela CA, Housman M, Ali A, et al. Vibrio cholerae Outer Membrane Vesicles Inhibit Bacteriophage Infection. DiRita VJ, editor. Journal of Bacteriology. 2018;200. doi:10.1128/JB.00792-17

11. Fischer T, Schorb M, Reintjes G, Kolovou A, Santarella-Mellwig R, Markert S, et al. Biopearling of Interconnected Outer Membrane Vesicle Chains by a Marine Flavobacterium. Cann I, editor. Applied and Environmental Microbiology. 2019;85. doi:10.1128/AEM.00829-19 
12. Møller J, Barnes A, Dalsgaard I, Ellis A. Characterisation of surface blebbing and membrane vesicles produced by Flavobacterium psychrophilum. Diseases of Aquatic Organisms. 2005;64: 201-209. doi:10.3354/dao064201

13. McCaig WD, Koller A, Thanassi DG. Production of Outer Membrane Vesicles and Outer Membrane Tubes by Francisella novicida. Journal of Bacteriology. 2013;195: 1120-1132. doi:10.1128/JB.02007-12

14. Laanto E, Penttinen RK, Bamford JK, Sundberg L-R. Comparing the different morphotypes of a fish pathogen - implications for key virulence factors in Flavobacterium columnare. BMC Microbiology. 2014;14: 170. doi:10.1186/1471-2180-14-170

15. Chang Y-W, Shaffer CL, Rettberg LA, Ghosal D, Jensen GJ. In Vivo Structures of the Helicobacter pylori cag Type IV Secretion System. Cell Reports. 2018;23: 673-681. doi:10.1016/j.celrep.2018.03.085

16. Hampton CM, Guerrero-Ferreira RC, Storms RE, Taylor JV, Yi H, Gulig PA, et al. The Opportunistic Pathogen Vibrio vulnificus Produces Outer Membrane Vesicles in a Spatially Distinct Manner Related to Capsular Polysaccharide. Frontiers in Microbiology. 2017;8. doi:10.3389/fmicb.2017.02177

17. Brown L, Wolf JM, Prados-Rosales R, Casadevall A. Through the wall: extracellular vesicles in Gram-positive bacteria, mycobacteria and fungi. Nature Reviews Microbiology. 2015;13: 620-630. doi:10.1038/nrmicro3480

18. Bhattacharya S, Baidya AK, Pal RR, Mamou G, Gatt YE, Margalit H, et al. A Ubiquitous Platform for Bacterial Nanotube Biogenesis. Cell Reports. 2019;27: 334-342.e10. doi:10.1016/j.celrep.2019.02.055

19. Dubey GP, Ben-Yehuda S. Intercellular Nanotubes Mediate Bacterial Communication. Cell. 2011;144: 590-600. doi:10.1016/j.cell.2011.01.015

20. Baidya AK, Bhattacharya S, Dubey GP, Mamou G, Ben-Yehuda S. Bacterial nanotubes: a conduit for intercellular molecular trade. Current Opinion in Microbiology. 2018;42: 1-6. doi:10.1016/j.mib.2017.08.006

21. Pande S, Shitut S, Freund L, Westermann M, Bertels F, Colesie C, et al. Metabolic crossfeeding via intercellular nanotubes among bacteria. Nature Communications. 2015;6. doi: $10.1038 /$ ncomms 7238

22. Benomar S, Ranava D, Cárdenas ML, Trably E, Rafrafi Y, Ducret A, et al. Nutritional stress induces exchange of cell material and energetic coupling between bacterial species. Nat Commun. 2015;6: 6283. doi:10.1038/ncomms7283

23. Baidya AK, Rosenshine I, Ben-Yehuda S. Donor-delivered cell wall hydrolases facilitate nanotube penetration into recipient bacteria. Nat Commun. 2020;11: 1938. doi:10.1038/s41467-020-15605-1 
24. Pal RR, Baidya AK, Mamou G, Bhattacharya S, Socol Y, Kobi S, et al. Pathogenic E. coli Extracts Nutrients from Infected Host Cells Utilizing Injectisome Components. Cell. 2019;177: 683-696.e18. doi:10.1016/j.cell.2019.02.022

25. Shetty A, Chen S, Tocheva EI, Jensen GJ, Hickey WJ. Nanopods: A New Bacterial Structure and Mechanism for Deployment of Outer Membrane Vesicles. Hensel M, editor. PLoS ONE. 2011;6: e20725. doi:10.1371/journal.pone.0020725

26. Marguet E, Gaudin M, Gauliard E, Fourquaux I, le Blond du Plouy S, Matsui I, et al. Membrane vesicles, nanopods and/or nanotubes produced by hyperthermophilic archaea of the genus Thermococcus. Biochemical Society Transactions. 2013;41: 436-442. doi:10.1042/BST20120293

27. Bar-Ziv R, Moses E. Instability and "Pearling" States Produced in Tubular Membranes by Competition of Curvature and Tension. Physical Review Letters. 1994;73: 1392-1395. doi:10.1103/PhysRevLett.73.1392

28. Pospíšil J, Vítovská D, Kofroňová O, Muchová K, Šanderová H, Hubálek M, et al. Bacterial nanotubes as a manifestation of cell death. Nature Communications. 2020;11. doi:10.1038/s41467-020-18800-2

29. Bos J, Cisneros LH, Mazel D. Real-time tracking of bacterial membrane vesicles reveals enhanced membrane traffic upon antibiotic exposure. Science Advances. 2021;7: eabd1033. doi:10.1126/sciadv.abd1033

30. Sivabalasarma S, Wetzel H, Nußbaum P, van der Does C, Beeby M, Albers S-V. Analysis of Cell-Cell Bridges in Haloferax volcanii Using Electron Cryo-Tomography Reveal a Continuous Cytoplasm and S-Layer. Front Microbiol. 2021;11: 612239. doi:10.3389/fmicb.2020.612239

31. Ding HJ, Oikonomou CM, Jensen GJ. The Caltech Tomography Database and Automatic Processing Pipeline. Journal of Structural Biology. 2015;192: 279-286. doi:10.1016/j.jsb.2015.06.016

32. Ortega DR, Oikonomou CM, Ding HJ, Rees-Lee P, Alexandria, Jensen GJ. ETDB-Caltech: A blockchain-based distributed public database for electron tomography. Promponas VJ, editor. PLOS ONE. 2019;14: e0215531. doi:10.1371/journal.pone.0215531

33. Fukumura T, Makino F, Dietsche T, Kinoshita M, Kato T, Wagner S, et al. Assembly and stoichiometry of the core structure of the bacterial flagellar type III export gate complex. Stock A, editor. PLOS Biology. 2017;15: e2002281. doi:10.1371/journal.pbio.2002281

34. Fabiani FD, Renault TT, Peters B, Dietsche T, Gálvez EJC, Guse A, et al. A flagellumspecific chaperone facilitates assembly of the core type III export apparatus of the bacterial flagellum. Stock A, editor. PLOS Biology. 2017;15: e2002267. doi:10.1371/journal.pbio.2002267 
35. Minamino T, Kawamoto A, Kinoshita M, Namba K. Molecular Organization and Assembly of the Export Apparatus of Flagellar Type III Secretion Systems. Berlin, Heidelberg: Springer Berlin Heidelberg; 2019. doi:10.1007/82_2019_170

36. Lertsethtakarn P, Ottemann KM, Hendrixson DR. Motility and Chemotaxis in Campylobacter and Helicobacter. Annual Review of Microbiology. 2011;65: 389-410. doi:10.1146/annurev-micro-090110-102908

37. Wang X, Han Q, Chen G, Zhang W, Liu W. A Putative Type II Secretion System Is Involved in Cellulose Utilization in Cytophaga hutchisonii. Frontiers in Microbiology. 2017;8. doi:10.3389/fmicb.2017.01482

38. Ghosal D, Kim KW, Zheng H, Kaplan M, Truchan HK, Lopez AE, et al. In vivo structure of the Legionella type II secretion system by electron cryotomography. Nature Microbiology. 2019 [cited 22 Nov 2019]. doi:10.1038/s41564-019-0603-6

39. Yuan F, Alimohamadi H, Bakka B, Trementozzi AN, Day KJ, Fawzi NL, et al. Membrane bending by protein phase separation. Proc Natl Acad Sci USA. 2021;118: e2017435118. doi: $10.1073 /$ pnas. 2017435118

40. Chang Y-W, Rettberg LA, Treuner-Lange A, Iwasa J, Søgaard-Andersen L, Jensen GJ. Architecture of the type IVa pilus machine. Science. 2016;351: $\operatorname{aad} 2001$. doi:10.1126/science.aad2001

41. Klein S, Wimmer BH, Winter SL, Kolovou A, Laketa V, Chlanda P. Post-correlation onlamella cryo-CLEM reveals the membrane architecture of lamellar bodies. Commun Biol. 2021;4: 137. doi:10.1038/s42003-020-01567-z

42. Kaplan M, Narasimhan S, de Heus C, Mance D, van Doorn S, Houben K, et al. EGFR Dynamics Change during Activation in Native Membranes as Revealed by NMR. Cell. 2016;167: 1241-1251.e11. doi:10.1016/j.cell.2016.10.038

43. Wiseman B, Nitharwal RG, Widmalm G, Högbom M. Structure of a full-length bacterial polysaccharide co-polymerase. Nat Commun. 2021;12: 369. doi:10.1038/s41467-02020579-1

44. Weaver SJ, Ortega DR, Sazinsky MH, Dalia TN, Dalia AB, Jensen GJ. CryoEM structure of the type IV a pilus secretin required for natural competence in Vibrio cholerae. Nature Communications. 2020;11. doi:10.1038/s41467-020-18866-y

45. Damer B, Deamer D. Coupled Phases and Combinatorial Selection in Fluctuating Hydrothermal Pools: A Scenario to Guide Experimental Approaches to the Origin of Cellular Life. Life. 2015;5: 872-887. doi:10.3390/life5010872

46. Cornell CE, Black RA, Xue M, Litz HE, Ramsay A, Gordon M, et al. Prebiotic amino acids bind to and stabilize prebiotic fatty acid membranes. Proceedings of the National Academy of Sciences. 2019;116: 17239-17244. doi:10.1073/pnas.1900275116 
47. Kaplan M, Sweredoski MJ, Rodrigues JPGLM, Tocheva EI, Chang Y-W, Ortega DR, et al. Bacterial flagellar motor PL-ring disassembly subcomplexes are widespread and ancient. Proceedings of the National Academy of Sciences. 2020; 201916935. doi:10.1073/pnas.1916935117

48. Shikuma NJ, Pilhofer M, Weiss GL, Hadfield MG, Jensen GJ, Newman DK. Marine Tubeworm Metamorphosis Induced by Arrays of Bacterial Phage Tail-Like Structures. Science. 2014;343: 529-533. doi:10.1126/science.1246794

49. Cornejo E, Subramanian P, Li Z, Jensen GJ, Komeili A. Dynamic Remodeling of the Magnetosome Membrane Is Triggered by the Initiation of Biomineralization. mBio. 2016;7. doi:10.1128/mBio.01898-15

50. Phillips DA, Zacharoff LA, Hampton CM, Chong GW, Malanoski AP, Metskas LA, et al. A Prokaryotic Membrane Sculpting BAR Domain Protein. Microbiology; 2020 Jan. doi:10.1101/2020.01.30.926147

51. Briegel A, Ortega DR, Tocheva EI, Wuichet K, Li Z, Chen S, et al. Universal architecture of bacterial chemoreceptor arrays. Proceedings of the National Academy of Sciences. 2009;106: 17181-17186. doi:10.1073/pnas.0905181106

52. Schrader JM, Shapiro L. Synchronization of Caulobacter Crescentus for Investigation of the Bacterial Cell Cycle. Journal of Visualized Experiments. 2015 [cited 15 Nov 2020]. doi: $10.3791 / 52633$

53. Carrión VJ, Perez-Jaramillo J, Cordovez V, Tracanna V, de Hollander M, Ruiz-Buck D, et al. Pathogen-induced activation of disease-suppressive functions in the endophytic root microbiome. Science. 2019;366: 606-612. doi:10.1126/science.aaw9285

54. Zheng SQ, Keszthelyi B, Branlund E, Lyle JM, Braunfeld MB, Sedat JW, et al. UCSF tomography: an integrated software suite for real-time electron microscopic tomographic data collection, alignment, and reconstruction. J Struct Biol. 2007;157: 138-147. doi:10.1016/j.jsb.2006.06.005

55. Mastronarde DN. Automated electron microscope tomography using robust prediction of specimen movements. J Struct Biol. 2005;152: 36-51. doi:10.1016/j.jsb.2005.07.007

56. Rohou A, Grigorieff N. CTFFIND4: Fast and accurate defocus estimation from electron micrographs. Journal of Structural Biology. 2015;192: 216-221. doi:10.1016/j.jsb.2015.08.008

57. Kremer JR, Mastronarde DN, McIntosh JR. Computer visualization of three-dimensional image data using IMOD. J Struct Biol. 1996;116: 71-76. doi:10.1006/jsbi.1996.0013

58. Nicastro D. The Molecular Architecture of Axonemes Revealed by Cryoelectron Tomography. Science. 2006;313: 944-948. doi:10.1126/science.1128618 
550

551

552

553

554

555

556

557

558

559

560

561

562

563

564

565

566

567

568

569

570

571

572
Tubes with a uniform diameter and an internal scaffold H. pylori fliP*
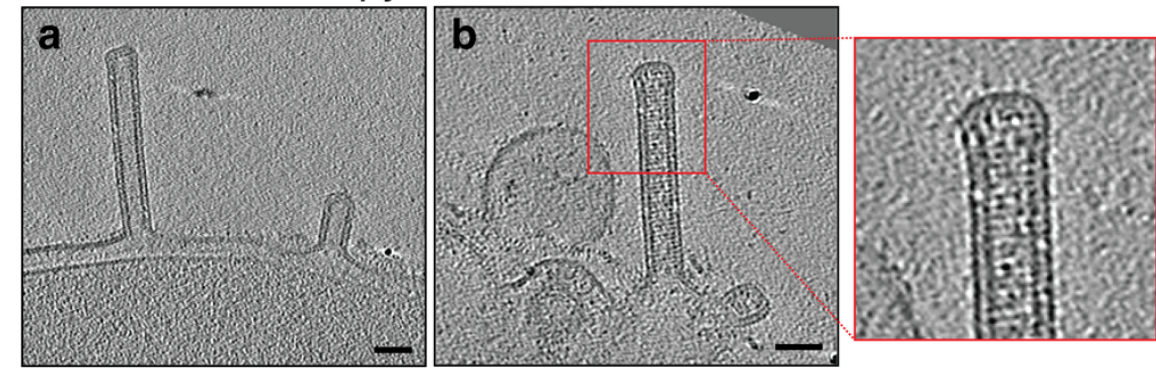

\section{Tubes with a uniform diameter and no clear internal scaffold}

M. xanthus
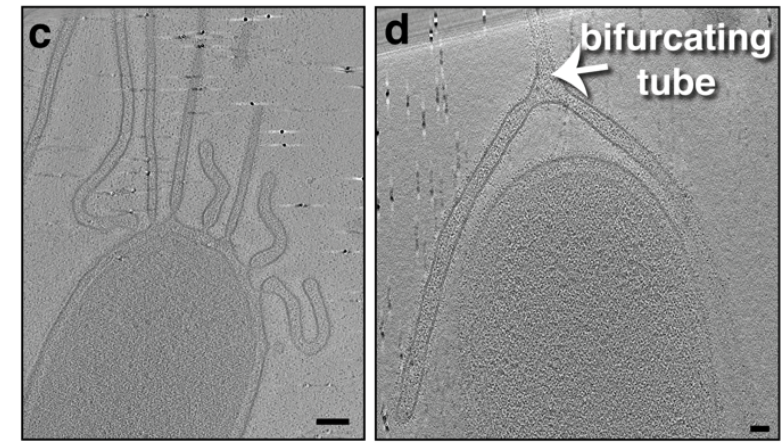

F. johnsoniae

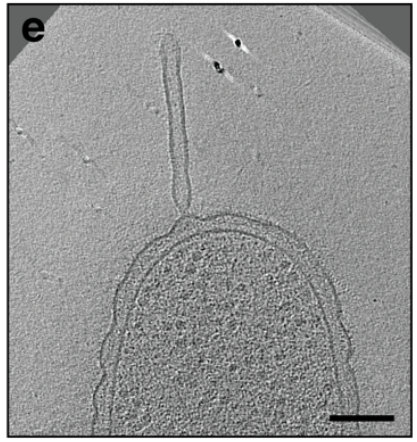

B. burgdorferi

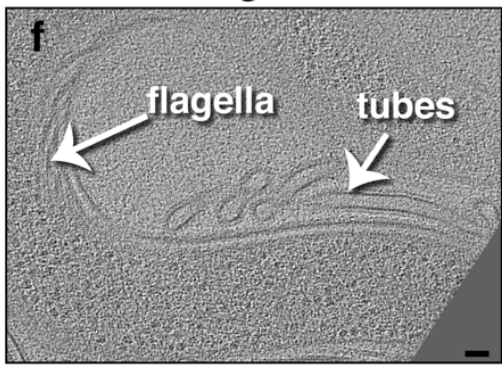

P. Iuteoviolacea
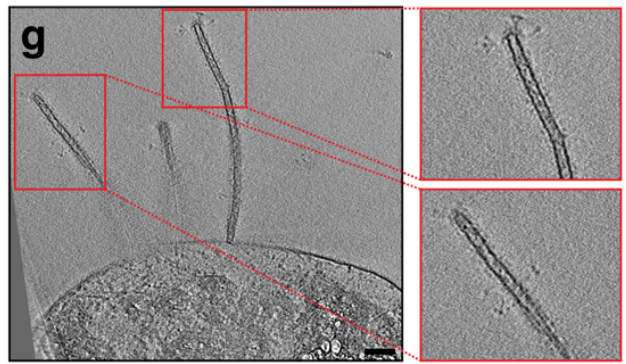

Teardrop-like tubular extensions

F. anhuiense
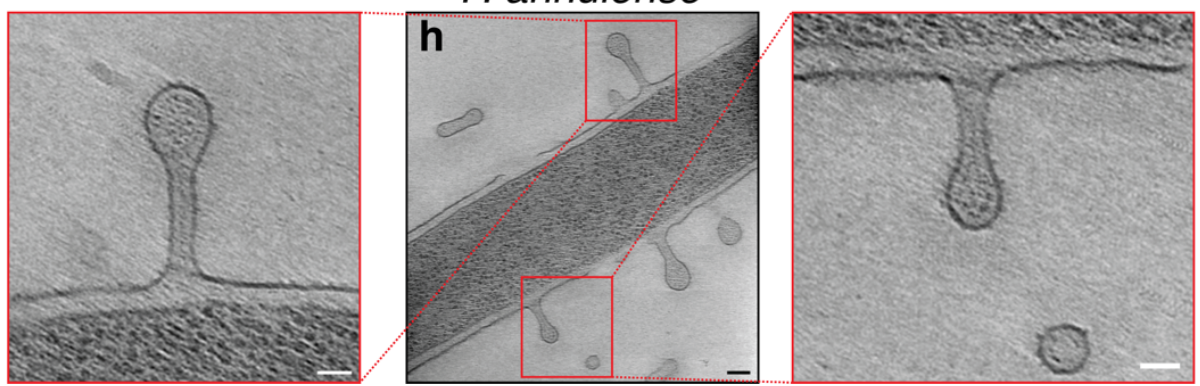


\section{$574 \quad$ Figure 2}

575

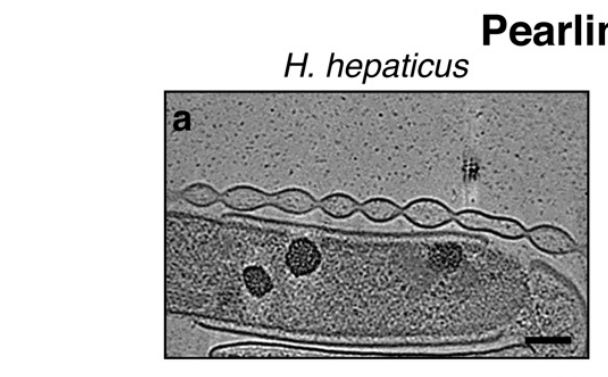

579

580

581

582

583
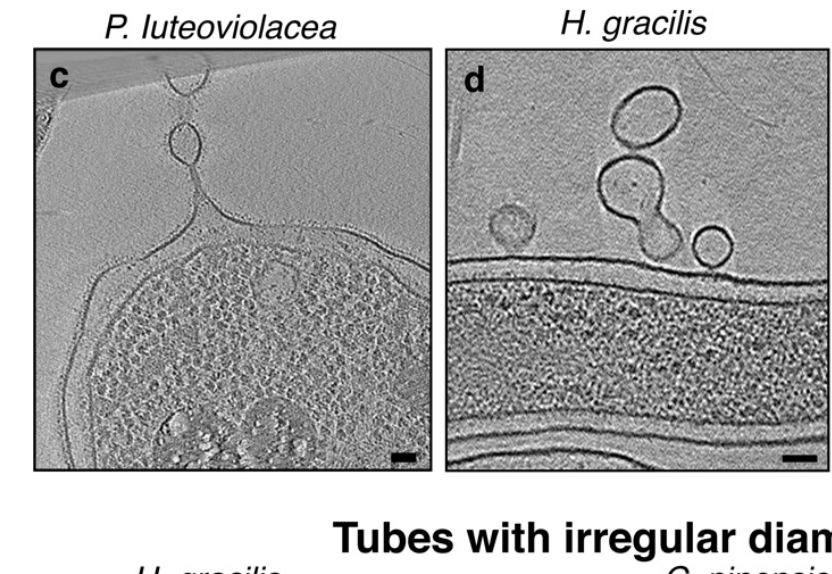

S. oneidensis

576

577

578

Tubes with irregular diameter

584

C. pinensis

585

586

587

588

589

H. gracilis

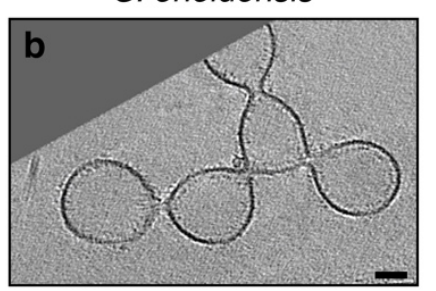

M. xanthus
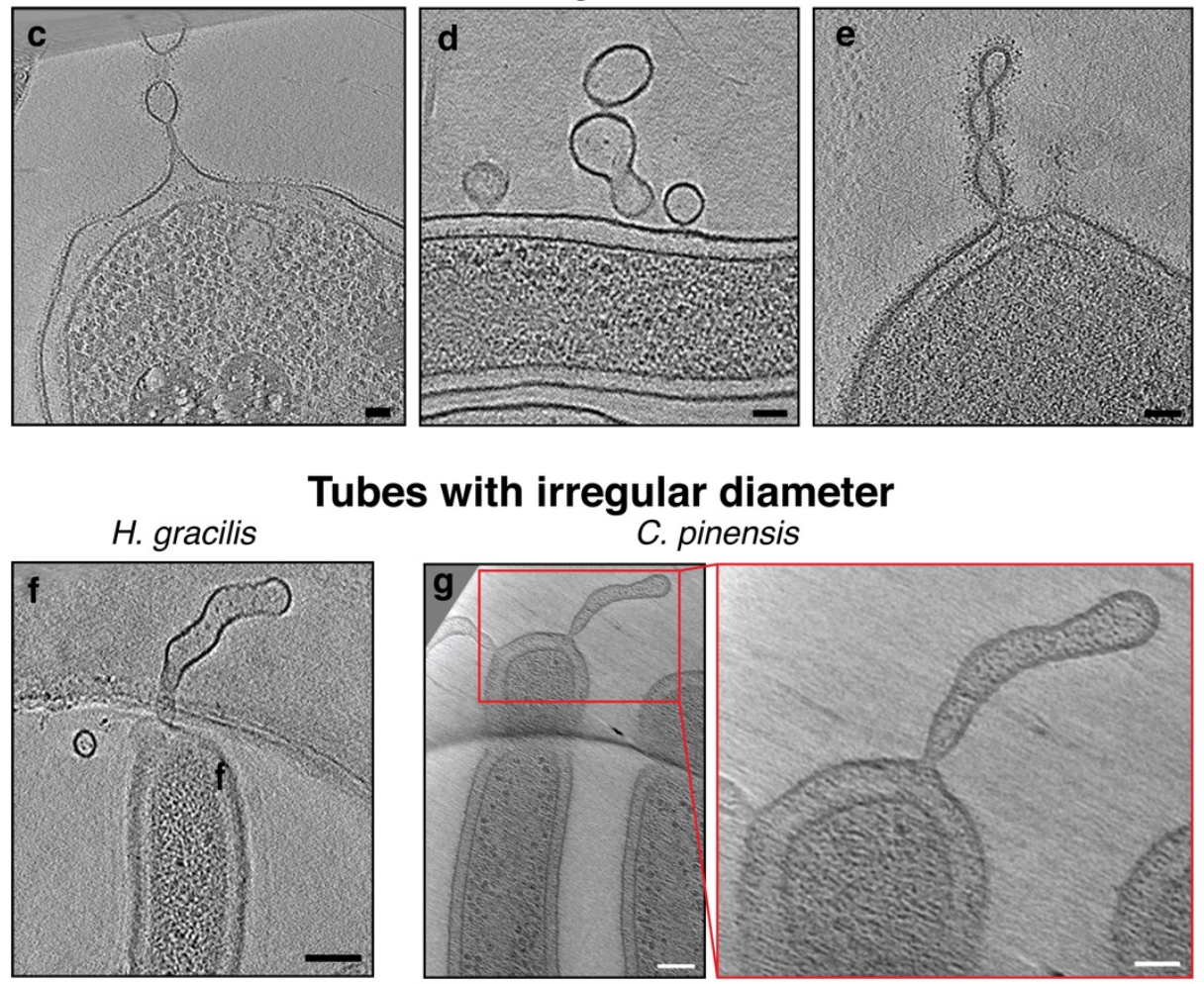

590

Interconnected chains of vesicles with neck-like bridges

591

B. burgdorferi
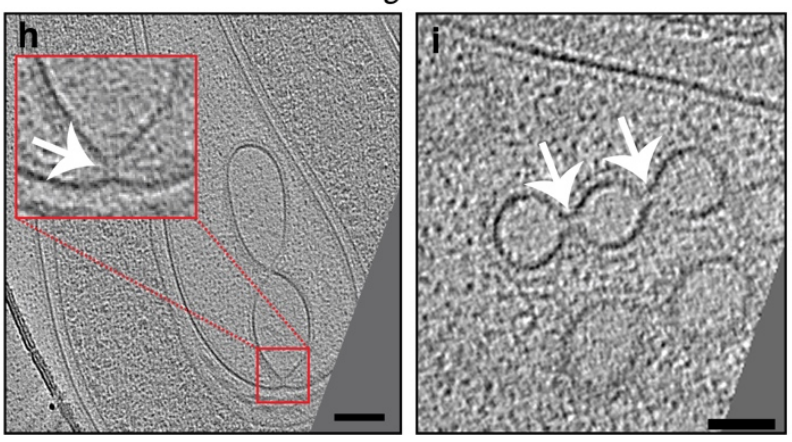


\section{$597 \quad$ Figure 3}
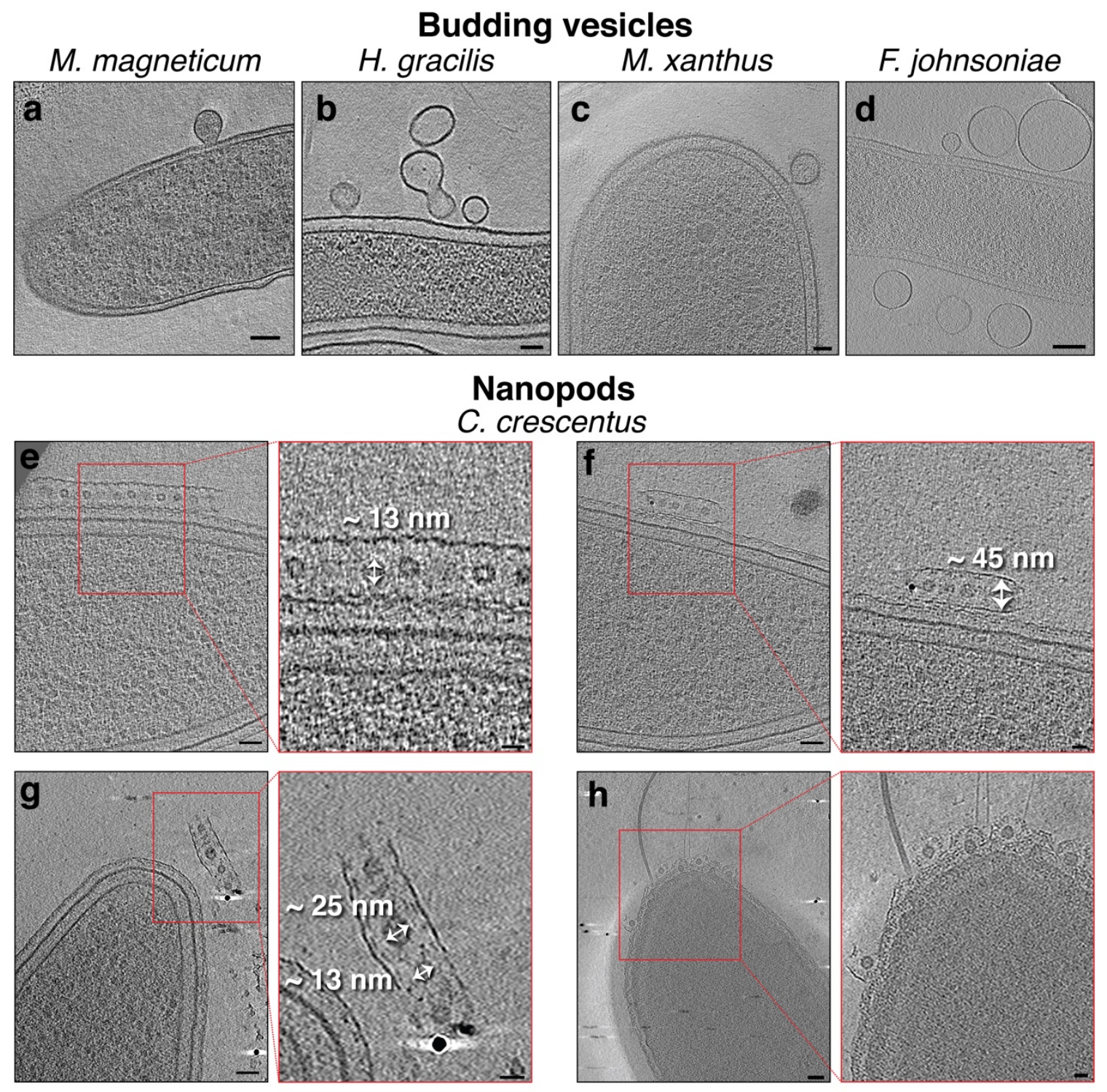

D. acidovorans

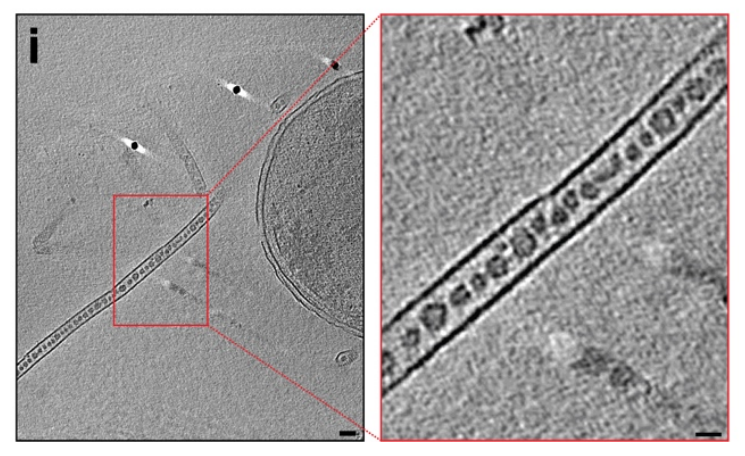




\section{Figure 4}

601 H. pylori fliP*

602

603

604

605

606
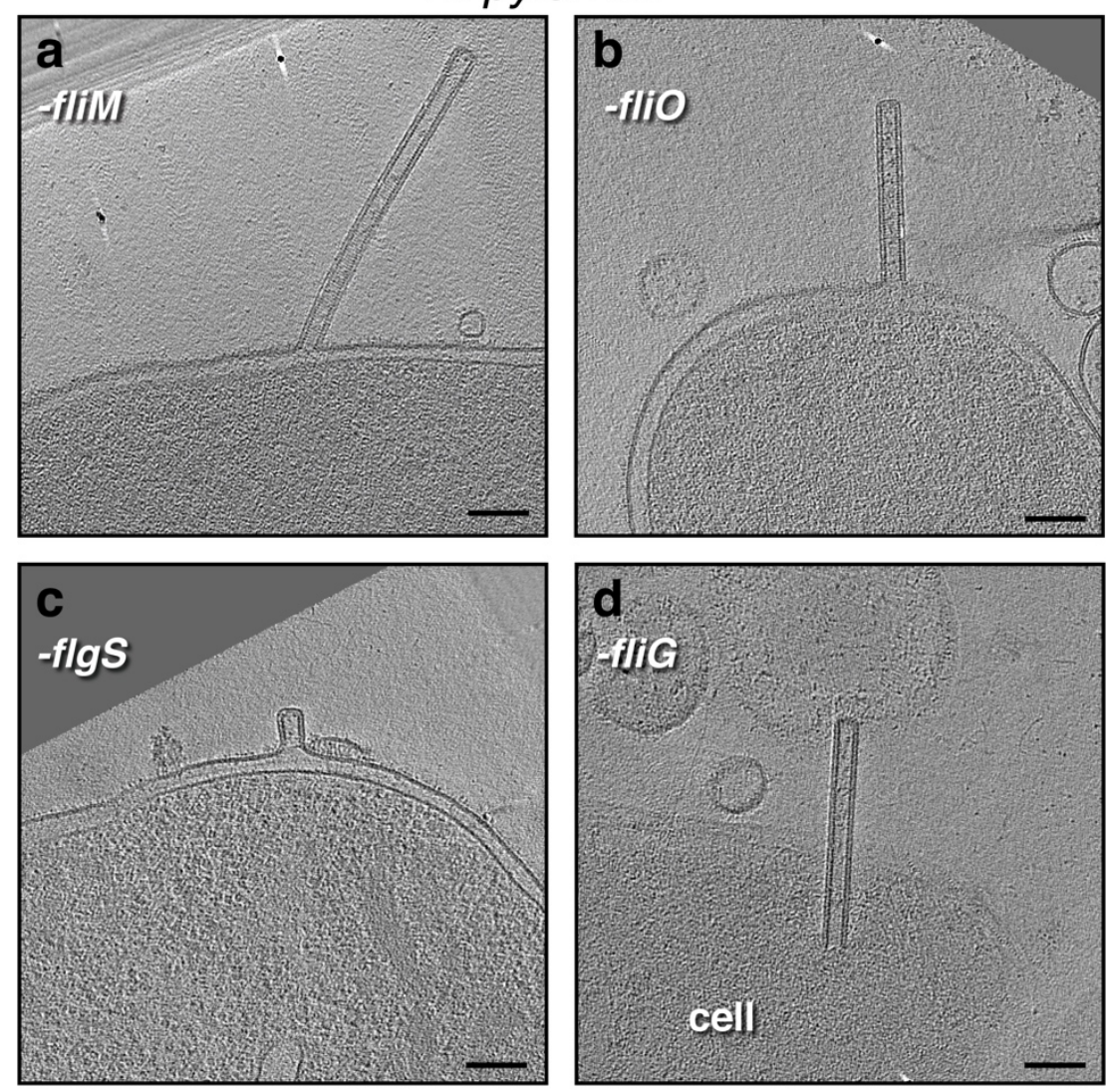

613

614
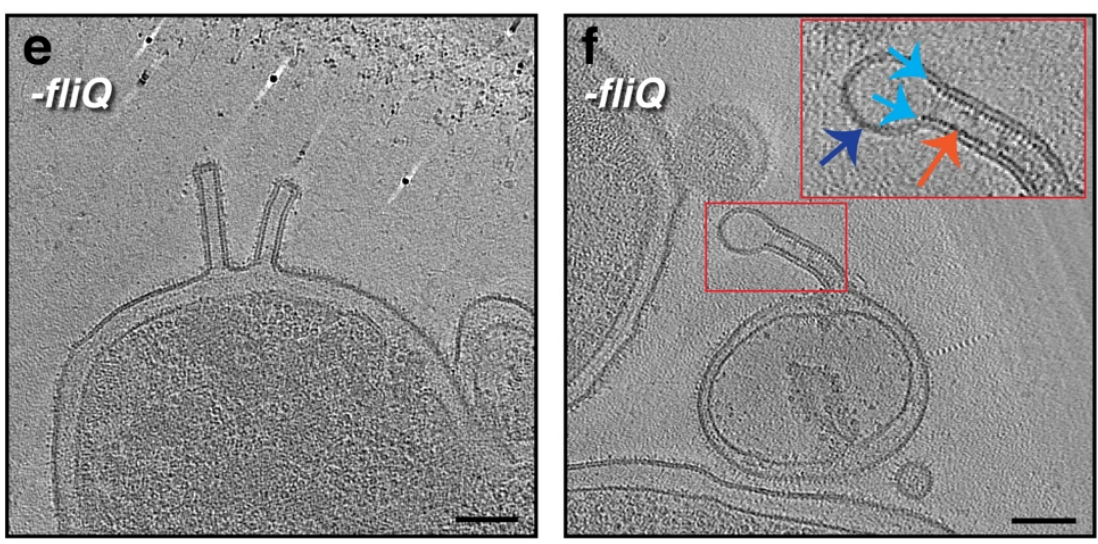
bioRxiv preprint doi: https://doi.org/10.1101/2021.07.13.452161; this version posted July 13, 2021. The copyright holder for this preprint (which was not certified by peer review) is the author/funder, who has granted bioRxiv a license to display the preprint in perpetuity. It is made available under aCC-BY 4.0 International license.

\section{$623 \quad$ Figure 5}

M. xanthus
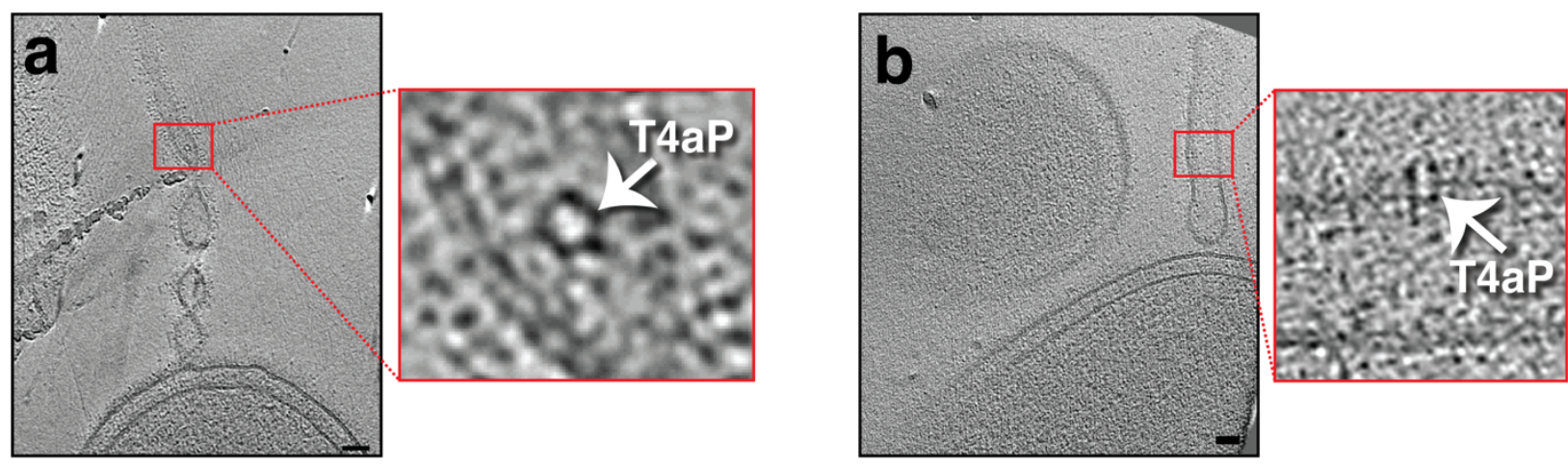

S. oneidensis
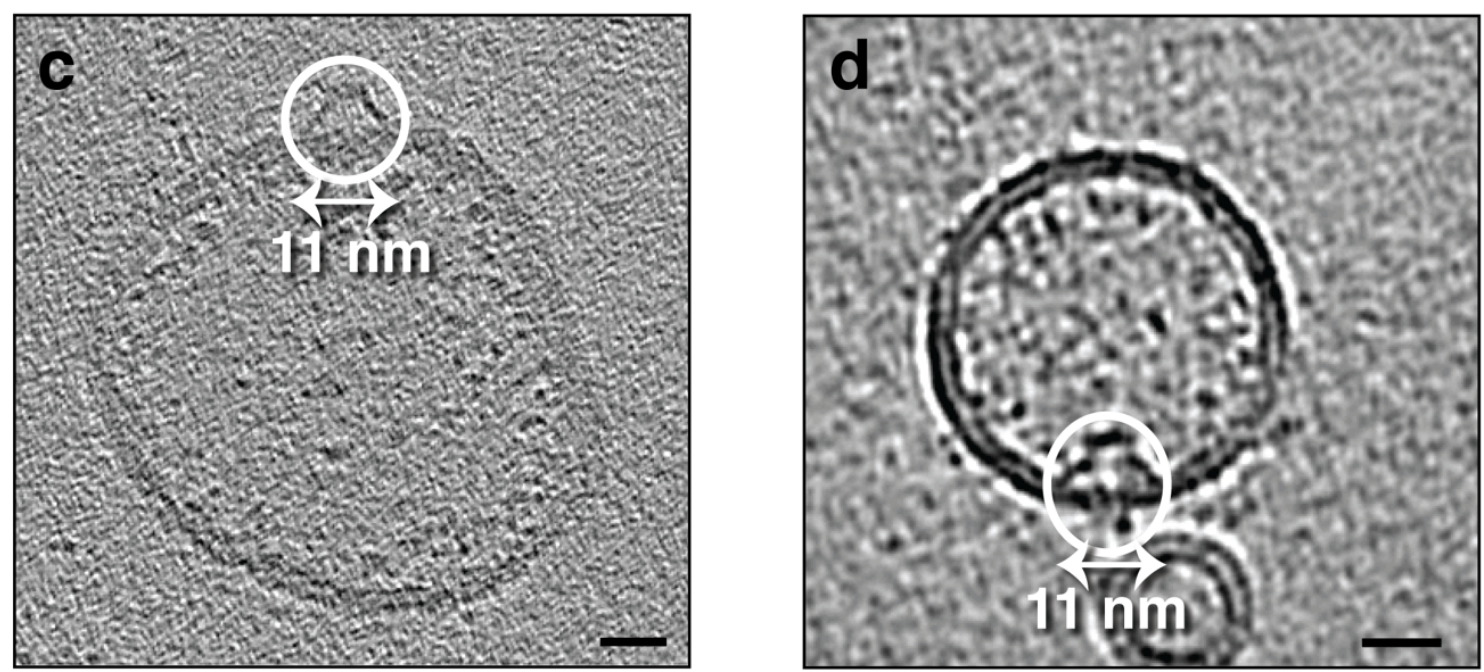

624

625

626

627

628

629

630

631 


\section{Figure 6}

633
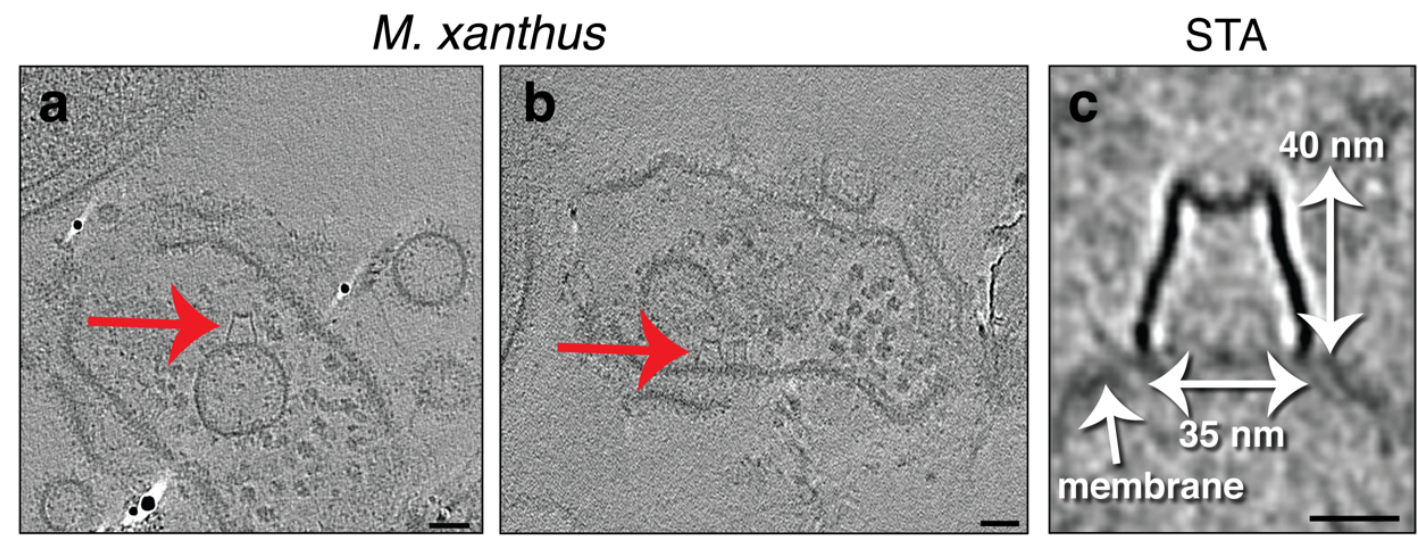

639

S. oneidensis

640

641

642

643
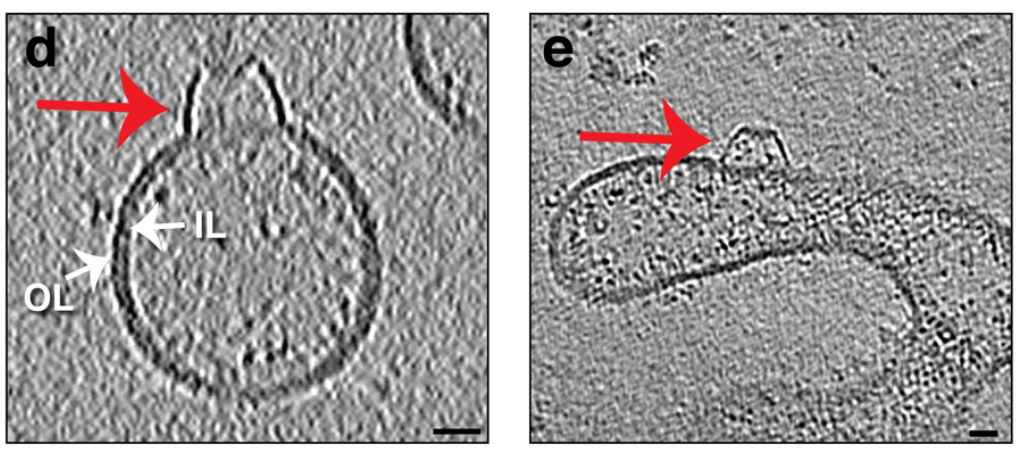

STA

644

645

646

647

648

649

\section{P. flexibilis}

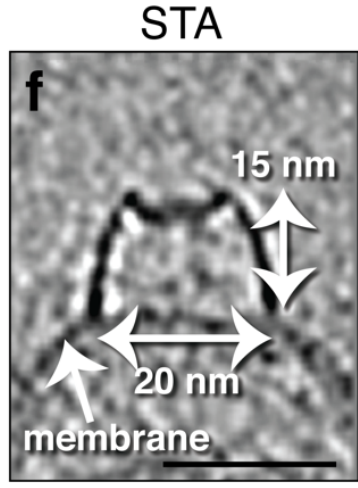

650

651

652

653
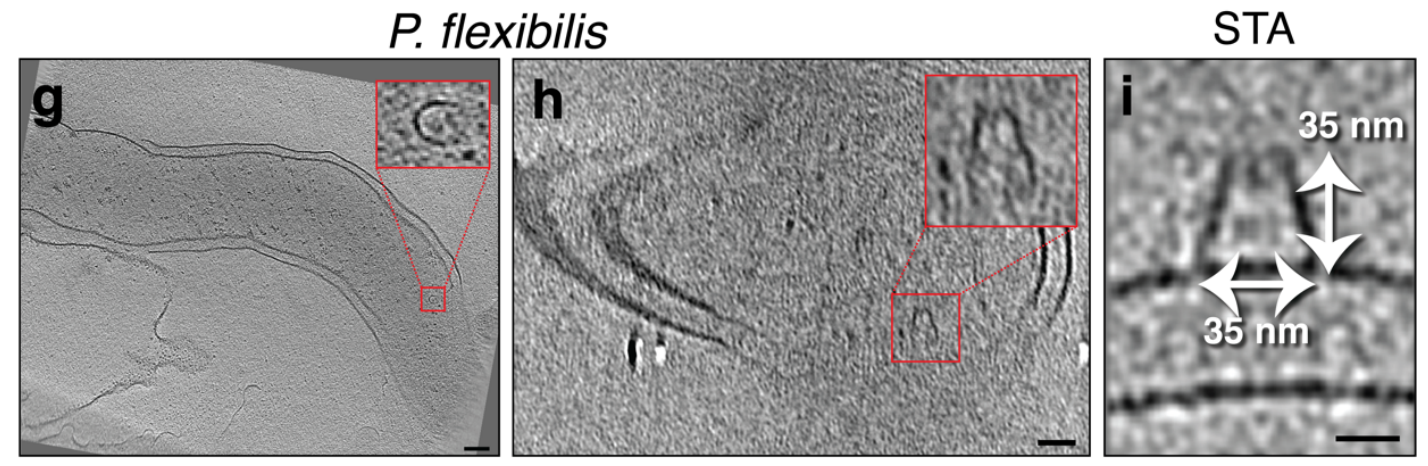

P. aeruginosa
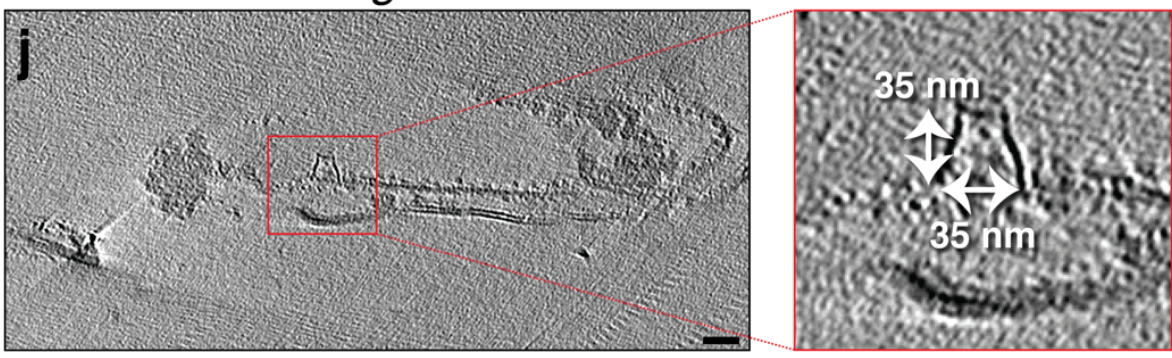

654 

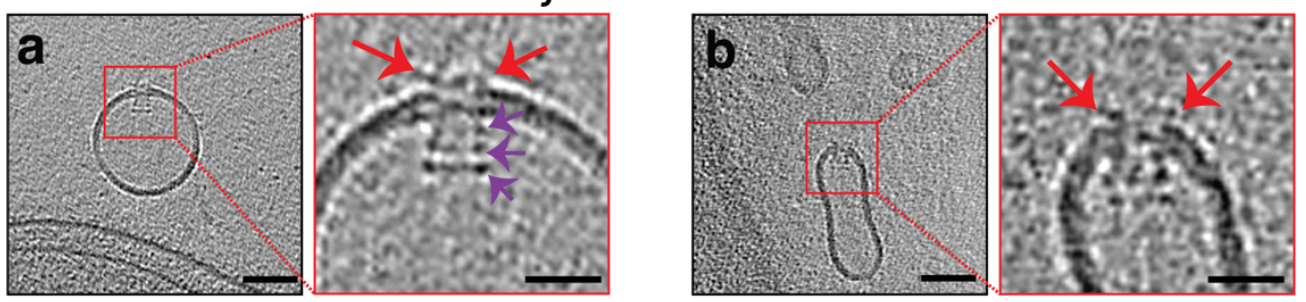

660

661

662
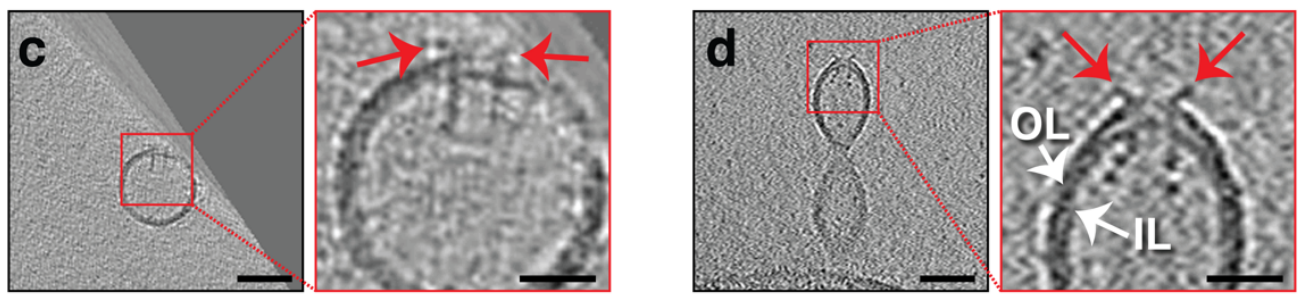

663

664
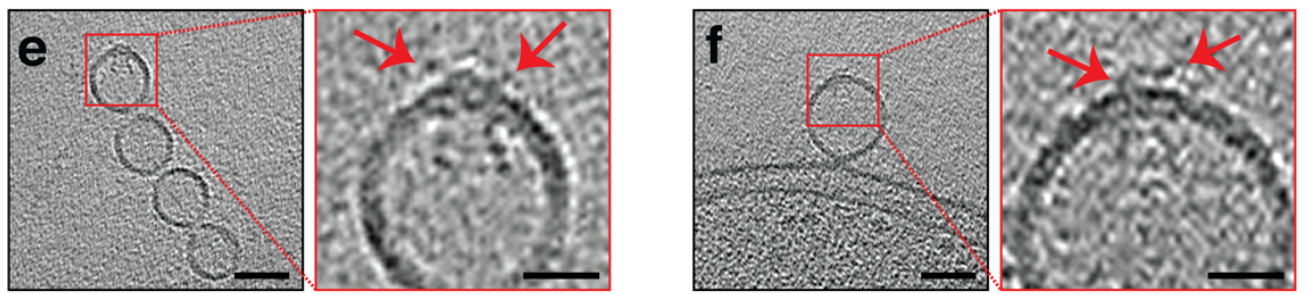

667

668
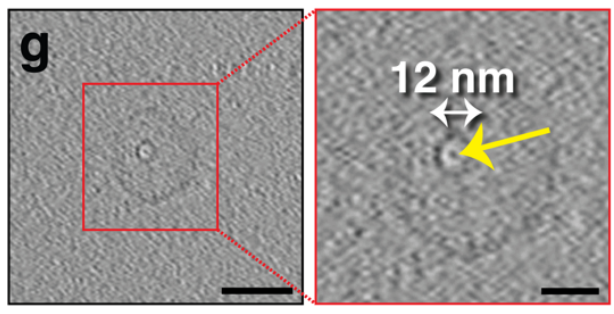

670

F. johnsoniae STA

671

672

673

674

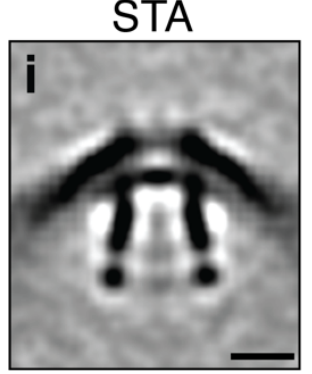

schematic

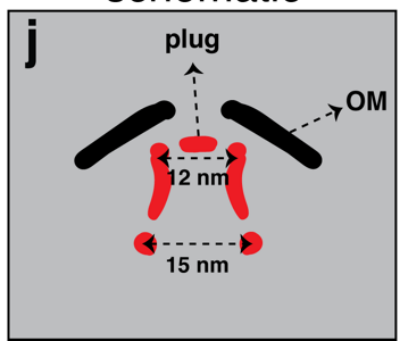

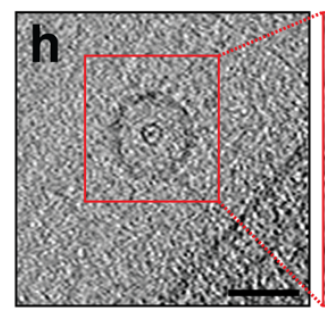

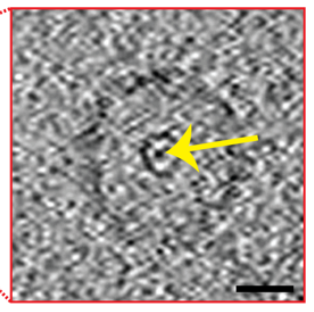

L. pneumophila STA

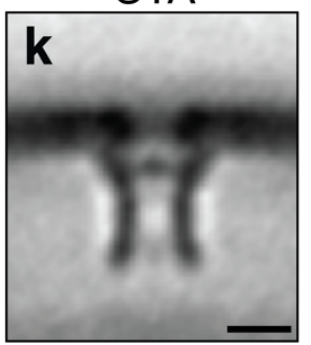

schematic

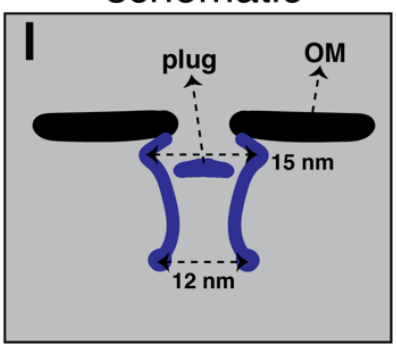

675

676

677 


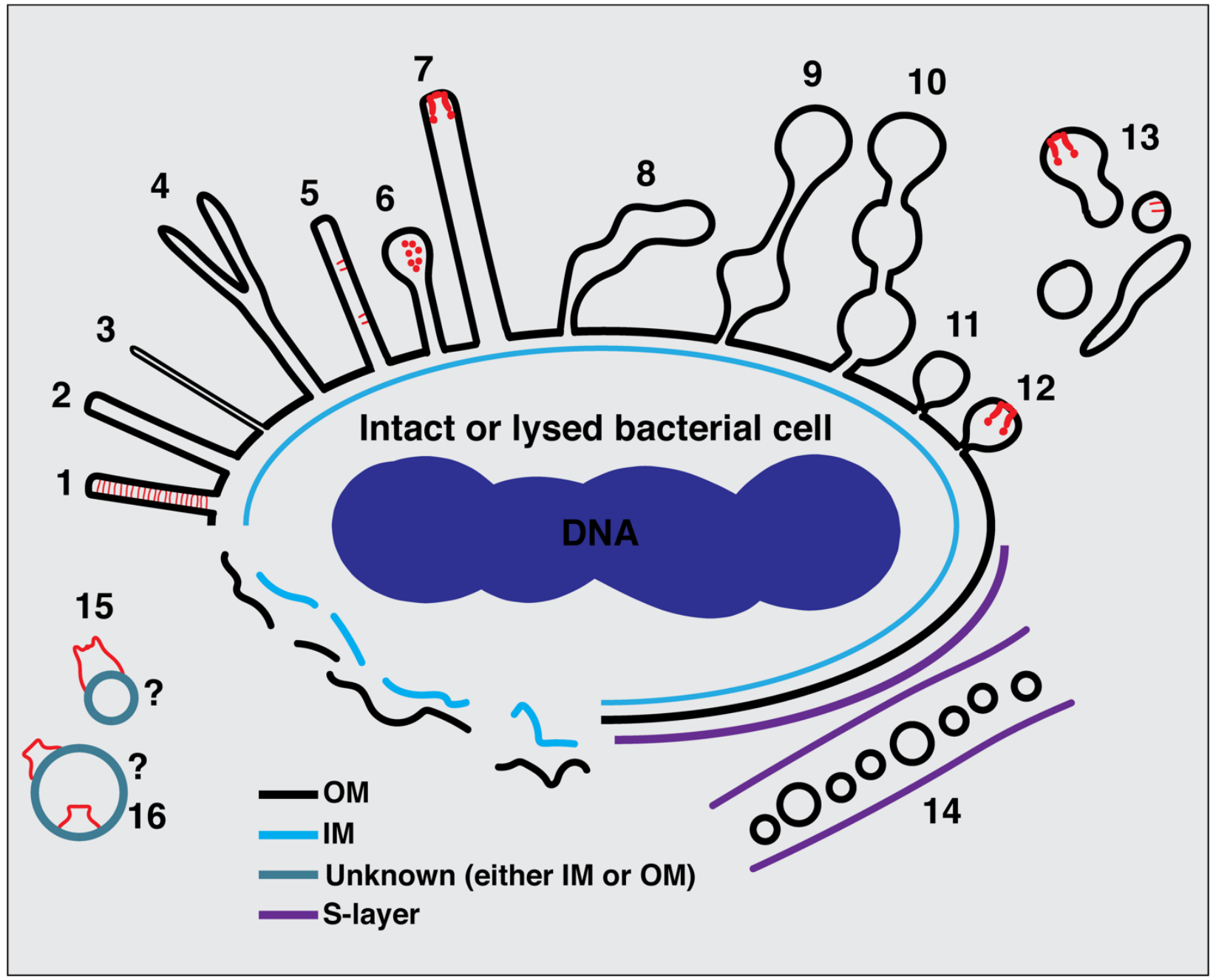


Figure legends:

Figure 1: Membrane tubes with a uniform diameter, either with or without an internal

scaffold. Slices through electron cryo-tomograms of the indicated bacterial species highlighting enlarged views of the same slice. Scale bars are $50 \mathrm{~nm}$, except in main panel (h) $100 \mathrm{~nm}$.

Figure 2: Pearling tubes, tubes with irregular diameter and vesicle chains with neck-like

connections. Slices through electron cryo-tomograms of the indicated bacterial species

701

Figure 3: Budding OMVs and nanopods. Slices through electron cryo-tomograms of the indicated bacterial species highlighting the presence of budding vesicles (a-d) or nanopods (e- i).

704 Scale bars are $50 \mathrm{~nm}$ in main panels and $20 \mathrm{~nm}$ in enlargements.

705

mutants. Slices through electron cryo-tomograms of the indicated $H$. pylori mutants (all in the 


\section{Figure 5: Randomly-located protein complexes on OMEs of M. xanthus and purified MVs of}

712 S. oneidensis. a \& b) Slices through electron cryo-tomograms of $M$. xanthus indicating the

713 presence of pearling tubes with top (a) and side (b) views of type IVa pilus basal bodies (T4aP).

714 Scale bars are $50 \mathrm{~nm} . \mathbf{c} \&$ d) Slices through electron cryo-tomograms of purified S. oneidensis

715 naturally-shed MEs and MVs highlighting the presence of trapezoidal structures on the outside (c)

716 and inside (d) of vesicles. Scale bars are $10 \mathrm{~nm}$.

Figure 6: Randomly-located protein complexes associated with lysed cells. Slices through

719 electron cryo-tomograms of lysed cells (a, b, $\mathbf{g}, \mathbf{h} \boldsymbol{\&} \mathbf{j})$ or purified MEs and MVs (d \&e) showing

720 the presence of membrane vesicles and lysed membranes with a crown-like complex (red arrows

721 and red-boxed enlargements). Scale bars: $50 \mathrm{~nm}(\mathrm{a}, \mathrm{b}, \mathrm{h}$ and j), $100 \mathrm{~nm}(\mathrm{~g}), 10 \mathrm{~nm}(\mathrm{~d}$ and e). c, f

722 \& i) Central slices through subtomogram averages (with two-fold symmetry along the Y-axis

723 applied) of 9 particles (c), 4 particles (f) or 3 particles (i) of the crown-like complex in the indicated

724 species. Scale bars are $20 \mathrm{~nm}$. OL=outer leaflet, $\mathrm{IL}=$ inner leaflet.

725

726 Figure 7: Secretin-like complexes located at the tip of OMEs and OMVs in F. johnsoniae.

727 Slices through electron cryo-tomograms of $F$. johnsoniae illustrating the presence of secretin-like

728 complexes (side views in a-f, top views in $\mathbf{g} \boldsymbol{\&} \mathbf{h}$ with yellows arrows pointing to the plug) in

729 OMEs and OMVs of $F$. johnsoniae. Red arrows point to the extracellular part of the complex.

730 Purple arrows in the enlargement in (a) point to the three periplasmic densities. Scale bars are 50

$731 \mathrm{~nm}$ in main panels and $20 \mathrm{~nm}$ in enlargements. i) A central slice through the subtomogram average

732 of 88 particles of the secretin-like complex (with two-fold symmetry along the Y-axis applied).

733 Scale bar is $10 \mathrm{~nm}$. j) A schematic representation of the STA shown in (i). k) A central slice 
734 through the subtomogram average of the secretin of the T2SS of L. pneumophila (EMD 20713,

735 see Ref. [38]). Scale bar is $10 \mathrm{~nm}$. l) A schematic representation of the STA shown in (k).

737 Figure 8: Summary of types of MEs and MVs identified in this study. 1) tubes with a uniform

738 diameter and with an internal scaffold; 2 \& 3) tubes with a uniform diameter but without an internal

739 scaffold; 4) bifurcating tubes; 5) tubes with randomly-located protein complexes (T4aP); 6)

740 teardrop-like extensions; 7) tubes with a secretin-like complex at their tip; 8) tubes with irregular

741 diameter; 9) pearling tubes; 10) interconnected chains of vesicles with 14-nm connectors; 11)

742 budding vesicles; 12) budding vesicles with a secretin-like complex at their tip; 13) various

743 disconnected membrane structures in the vicinity of bacterial cells; 14) nanopods in species with

744 an inner membrane (IM), outer membrane (OM), and S-layer; 15) membrane structures with a

745 crown-like complex from lysed cells; 16) purified OMVs with trapezoidal complexes. The

746 question marks in (15) and (16) indicate the difficulty of determining whether a membrane

747 structure from lysed cells or purified vesicles originated from the IM or the OM or is in its original 748 topology. 
Supporting information:

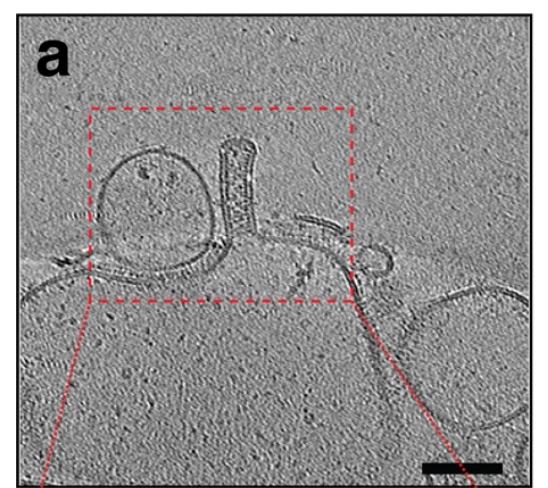

H. pylori fliP*
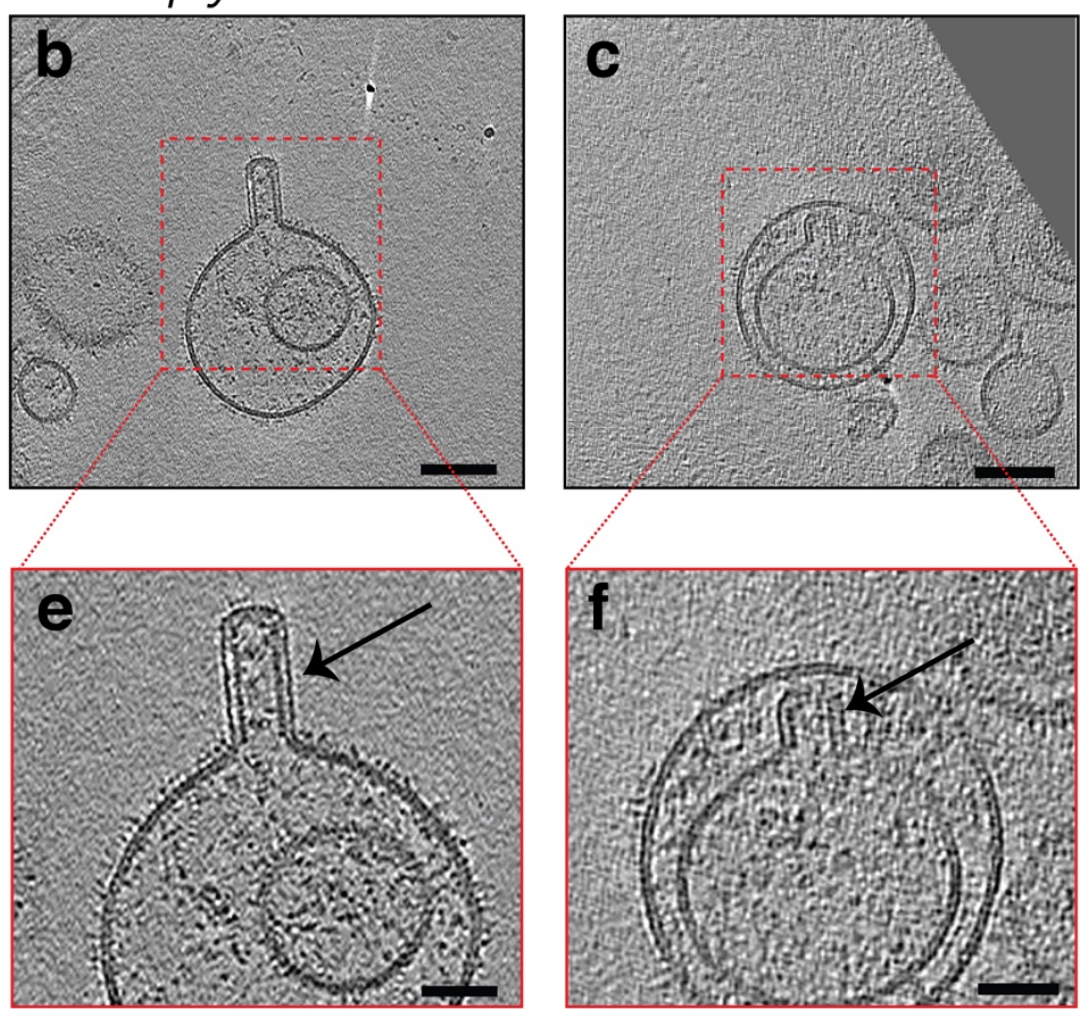

Figure S1: Slices through electron cryo-tomograms of lysed H. pylori cells illustrating the

753 presence of OM tubes in vesicles resulting from cell lysis (black arrows). Dashed red arrow in (d)

754 points to the scaffold structure inside the tube. Scale bars are $100 \mathrm{~nm}$ in (a-c) and $50 \mathrm{~nm}$ in (d-f). 
M. xanthus

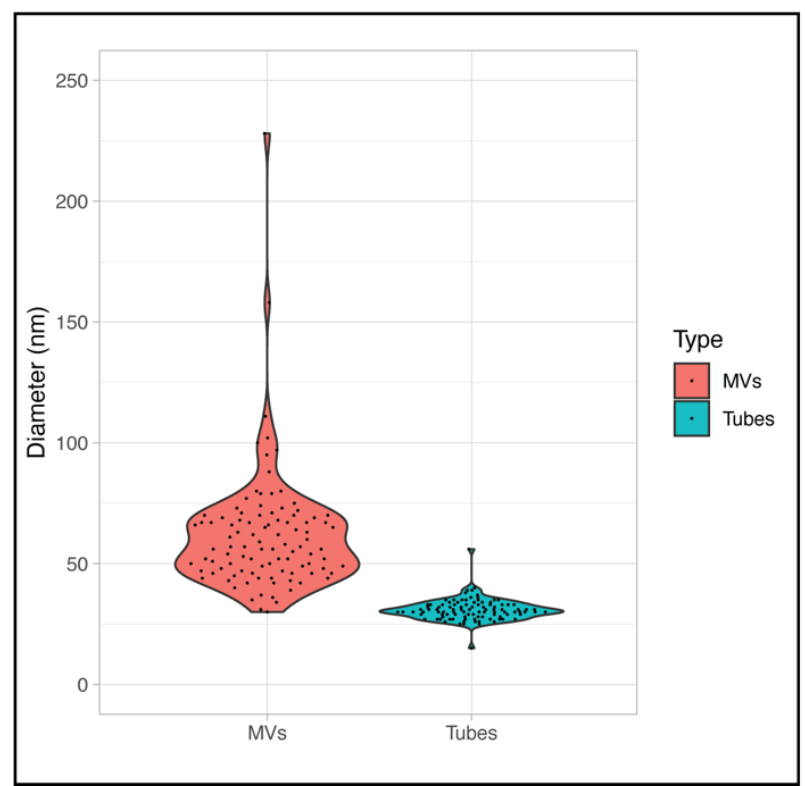

F. johnsoniae

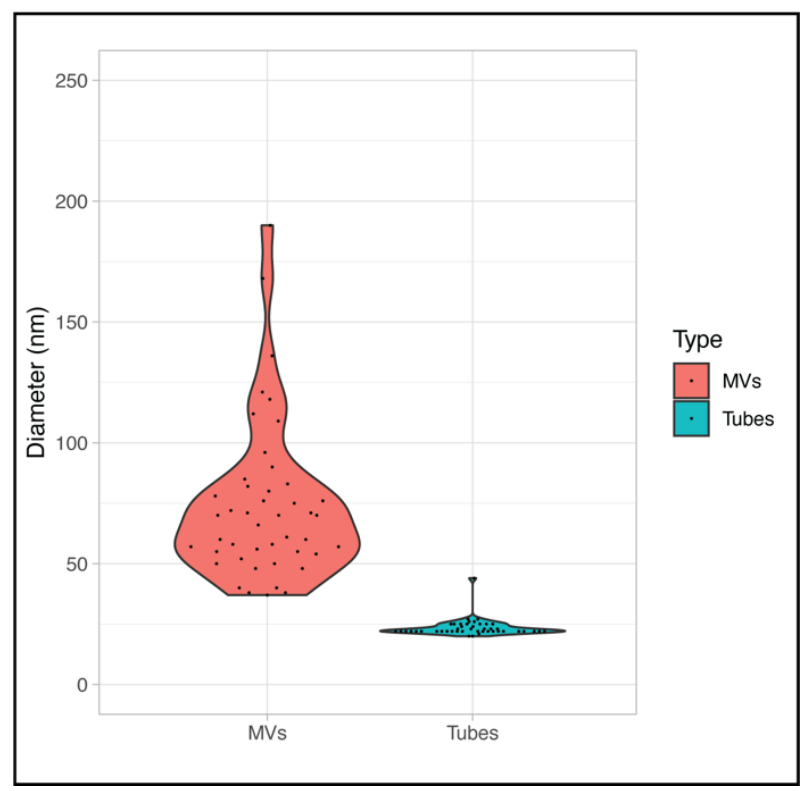

763 Figure S2: Violin plots of the sizes of OMVs and OM tubes in M. xanthus (100 randomly picked-

764 examples of each) and $F$. johnsoniae (45 randomly-picked examples of each). For both species, $765 \mathrm{p}<0.001$ (determined using t-Test: Two-sample assuming unequal variances). 
S. oneidensis

778
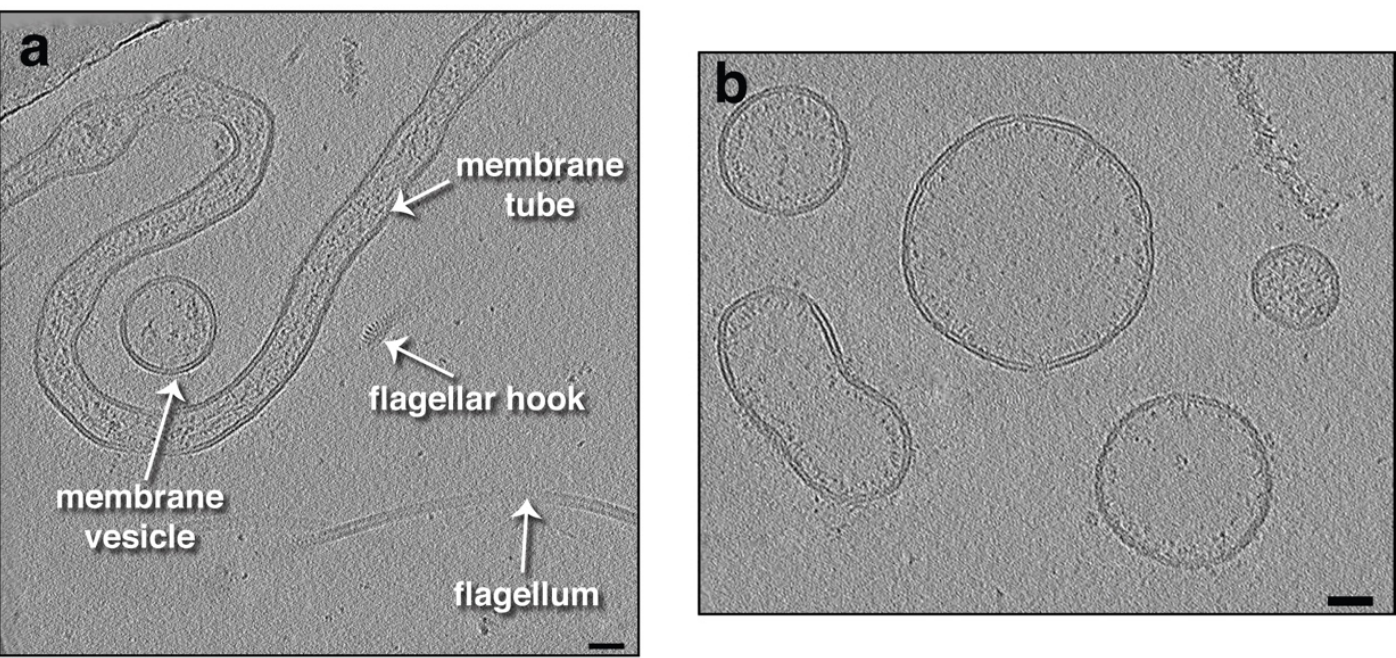

M. xanthus

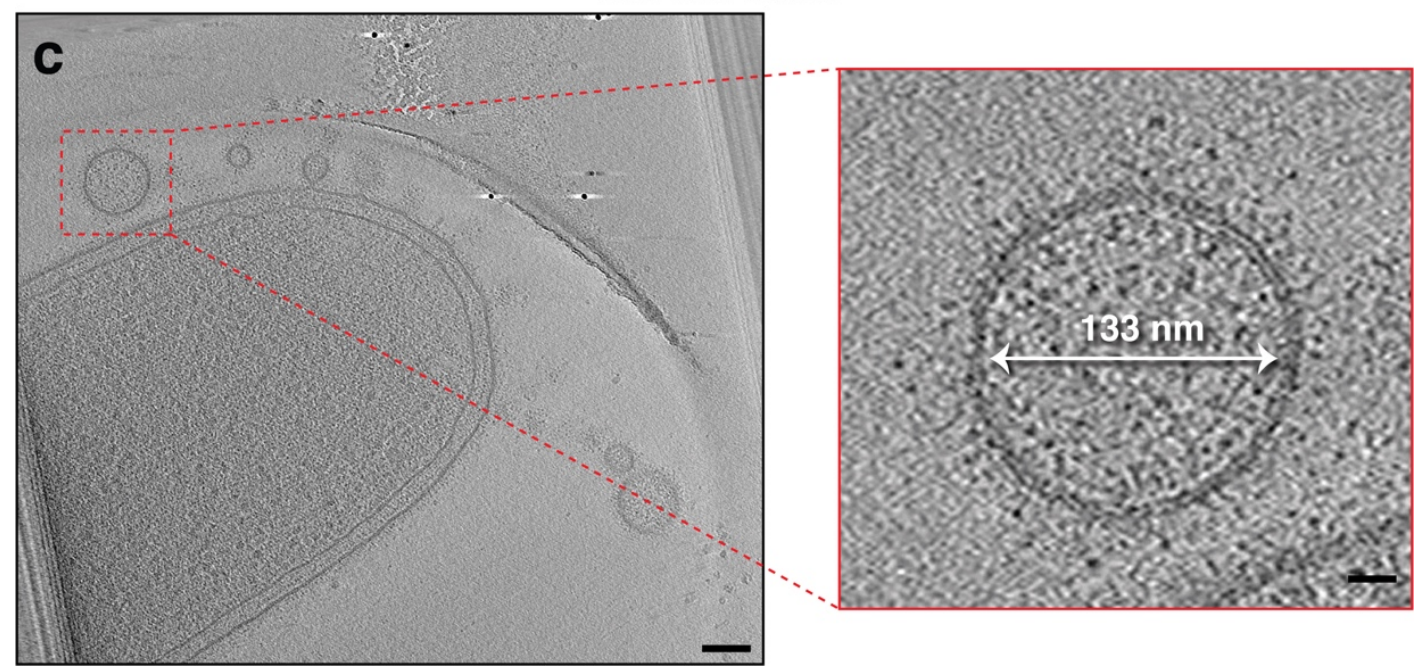

793 Figure S3: a \& b) Slices through electron cryo-tomograms of purified MEs and MVs from $S$.

796 right. 


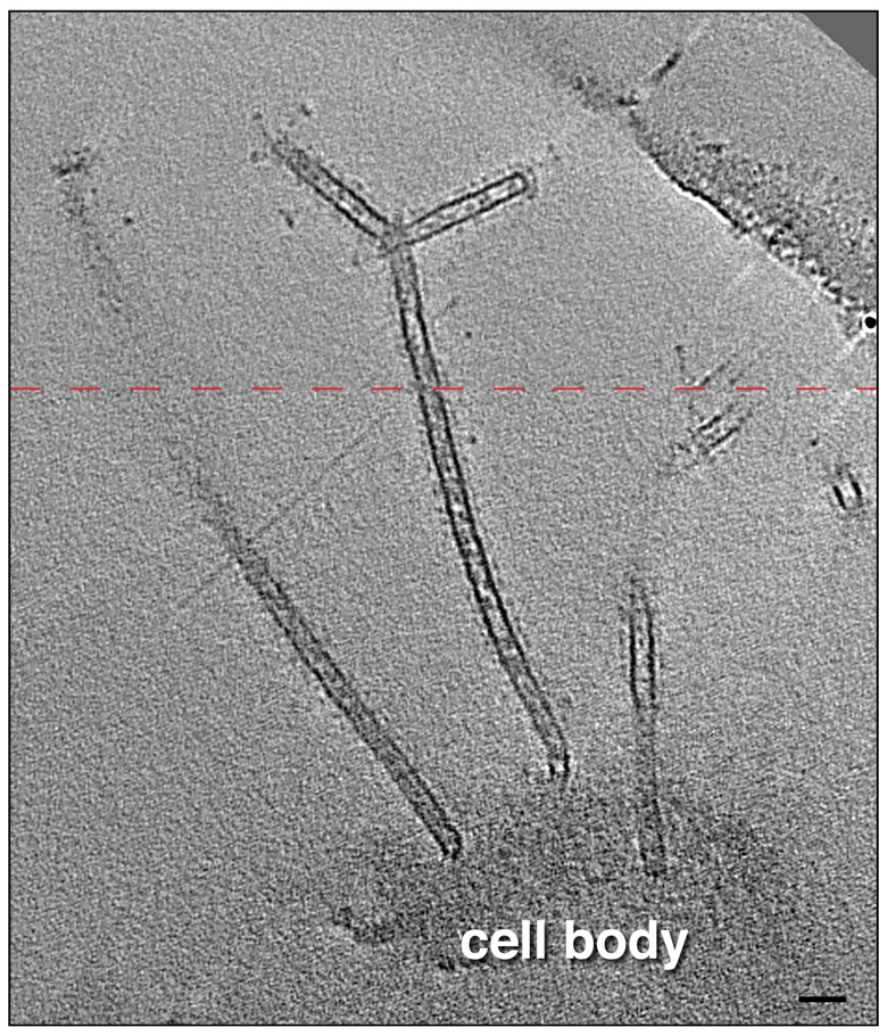

812 Figure S4: A slice through an electron cryo-tomogram of a lysed $P$. luteoviolacea cell illustrating

813 a bifurcated 20-nm wide membrane tube. Scale bar is $50 \mathrm{~nm}$. Dashed red line indicates a composite

814 image of two slices through the tomogram at different $\mathrm{z}$-heights.

\section{5}




\section{$P$. aeruginosa}

824

825

826
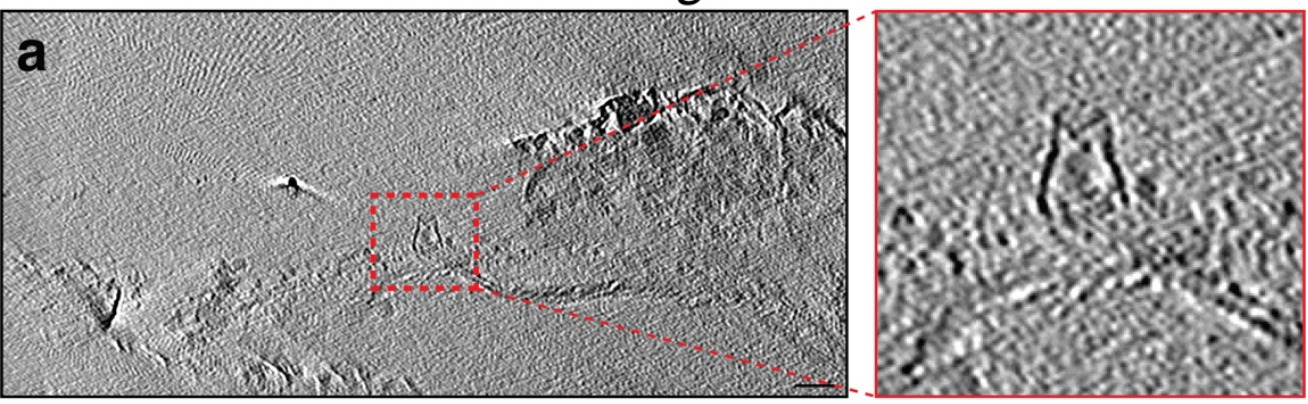

828

829

830

831

832

833
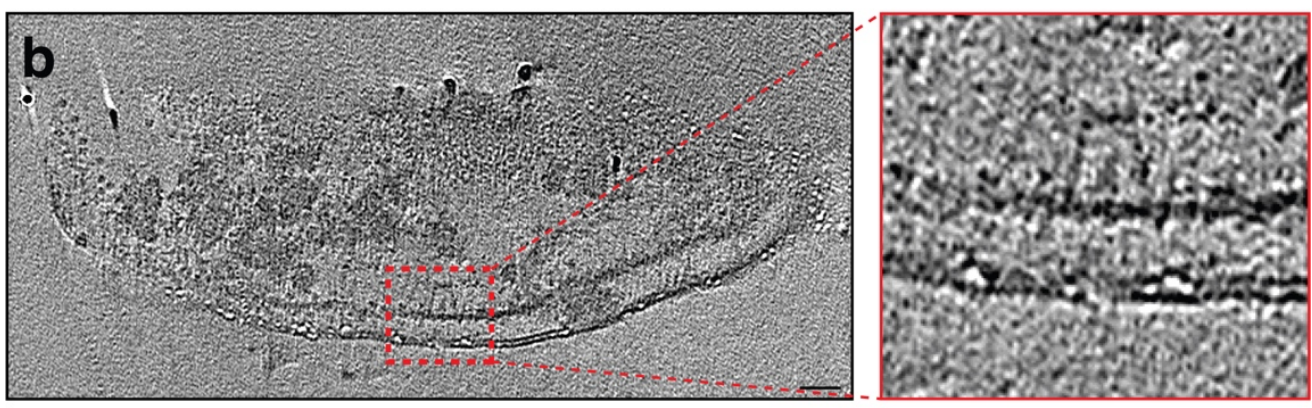

834

835

836
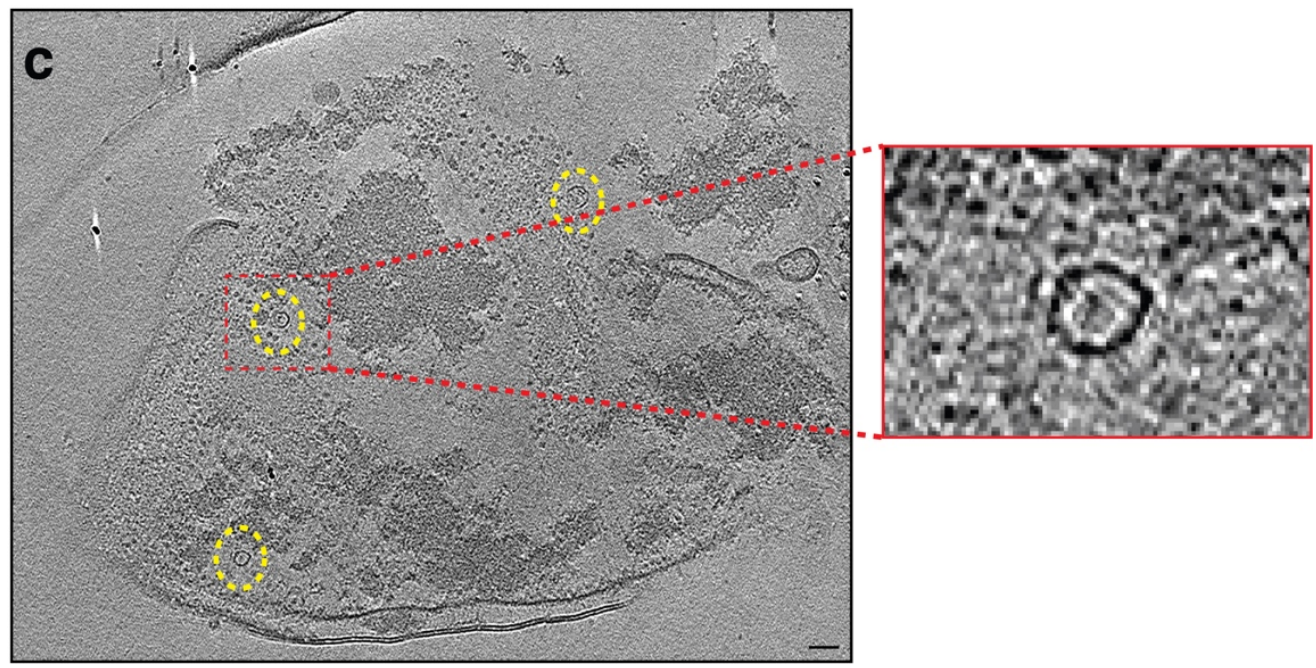

841 Figure S5: Slices through electron cryo-tomograms of lysed $P$. aeruginosa cells indicating the

842 presence of crown-like structures in side views ( $\mathbf{a} \& \mathbf{b})$ and top view (c, dashed yellow ellipses).

843 Panels on the right are enlargements of the boxed areas. Scale bars are $50 \mathrm{~nm}$. 


\section{F. johnsoniae}
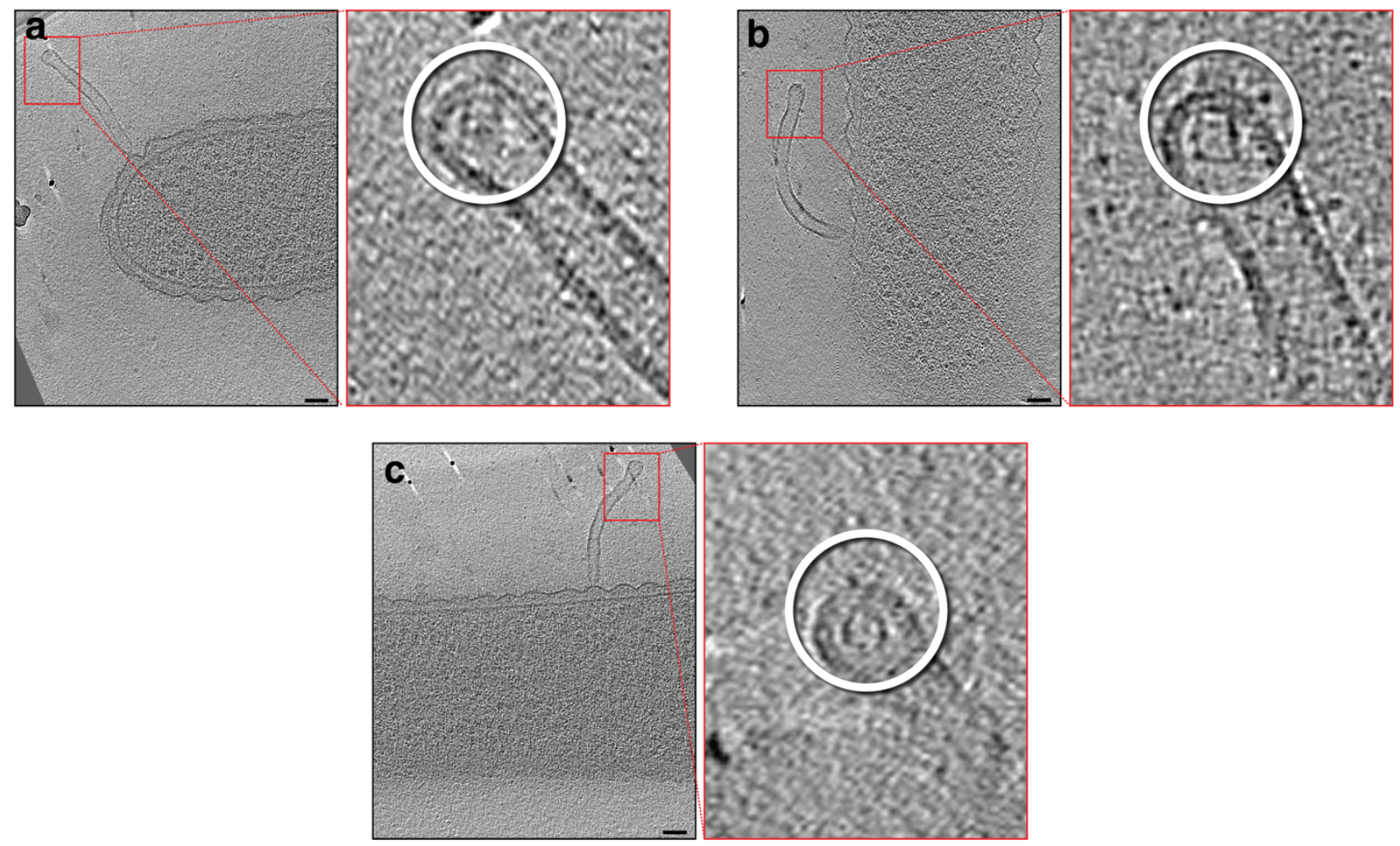

847 Figure S6: Slices through electron cryo-tomograms of $F$. johnsoniae (with wavy OM) illustrating

848 tubes stemming from cells with secretin-like complexes at their tips, as highlighted in the

849 enlargements on the right (white circles). Note that the rotation of the slices on the left is optimized

850 to show the full tube stemming from the cell, while the rotation of the enlargements on the right is

851 optimized to show the best view of the secretin-like complex. Scale bars are $50 \mathrm{~nm}$. 

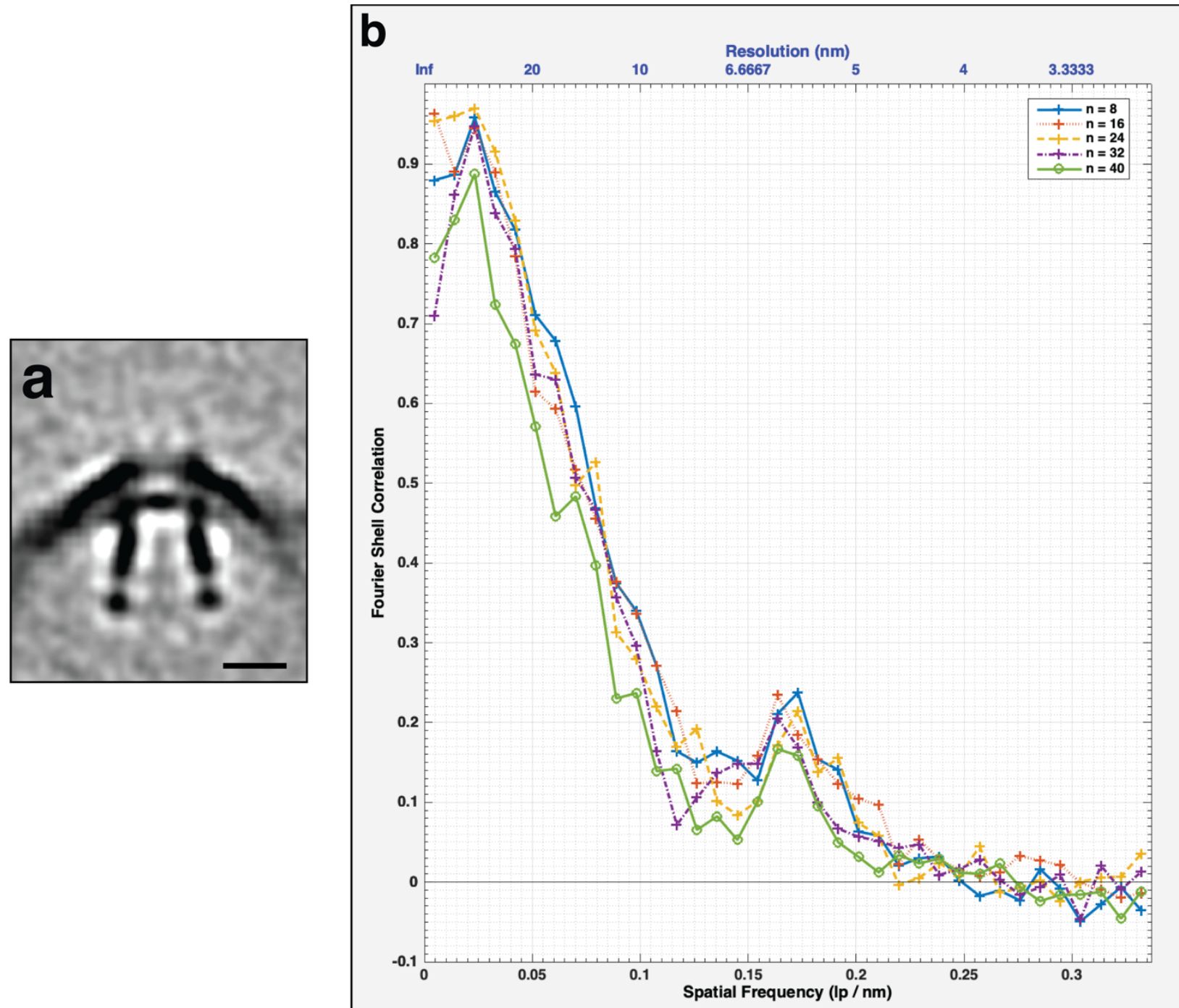

Figure S7: a) Central slice through the unsymmetrized subtomogram average of the secretin-like complex present in OM extensions in F. johnsoniae. Scale bar is $10 \mathrm{~nm}$. b) FSC curve of the

862 subtomogram average shown in (a). The different colored curves represent different subsets of 863 particles. 


\section{Supplementary movies:}

870 Movie S1: An electron cryo-tomogram of an M. xanthus cell with multiple outer membrane tubes

871 stemming from the cell.

872

873 Movie S2: An electron cryo-tomogram of an $F$. johnsoniae cell with outer membrane tubes 874 stemming from the cell. Note the wavy outer membrane of the cell.

875

876 Movie S3: An electron cryo-tomogram of an M. xanthus cell with a pearling outer membrane tube

877 stemming from the cell.

878

879 Movie S4: An electron cryo-tomogram of an M. xanthus cell with multiple branched outer 880 membrane tubes stemming from the cell.

881

882 Movie S5: An electron cryo-tomogram of a C. crescentus cell with a nanopod (black arrow) close 883 to the cell.

885 Movie S6: An electron cryo-tomogram of an $F$. johnsoniae cell highlighting the presence of 886 secretin-like particles at the tips of outer membrane tubes. 


\section{Materials and Methods:}

\section{Strains and growth conditions}

893 H. gracilis cells were grown as described in reference [47]. P. luteoviolacea were grown as

894 described in reference [48]. M. magneticum were grown as described in reference [49]. P. flexibilis

895706570 were grown in lactose growth medium. Shewanella oneidensis MR-1 cells were grown, as

896 detailed in reference [50], in Luria Bertani (LB) media under aerobic conditions at $30^{\circ} \mathrm{C}$ with

897 shaking at $200 \mathrm{rpm}$ until they reached $\mathrm{OD}_{600}$ of $\sim 3$. Myxococcus xanthus PilY1.3-sfGFP, M.

898 xanthus $\Delta t s a P$, and M.xanthus SA6892 strains were grown as described in reference [40]. Borrelia

899 burgdorferi B31 ATCC 35210 and Helicobacter hepaticus ATCC 51449 cells were grown in

900 standard media (see reference [51] and references therein).

901

902 Caulobacter crescentus was cultured in $\mathrm{M} 2 \mathrm{G}$ and $\mathrm{M} 2$ media (prepared as described in reference

903 [52].) $5 \mathrm{~mL}$ of $\mathrm{M} 2 \mathrm{G}$ were inoculated with a frozen stock of C. crescentus NA 1000 and grown

904 overnight at $28^{\circ} \mathrm{C} .5 \mathrm{~mL}$ of the overnight culture was diluted in $15 \mathrm{~mL} \mathrm{M} 2 \mathrm{G}$ and grown at $28^{\circ} \mathrm{C}$

905 with a shaking speed of $200 \mathrm{rpm}$ for $\sim 2$ hours until mid-log phase $\left(\mathrm{OD}_{600}\right.$ 0.4-0.5). The sample

906 was then centrifuged at $5200 \times \mathrm{g}$ for 6 minutes at $4{ }^{\circ} \mathrm{C}$ (same temperature for all subsequent

907 centrifugation steps) and the pellet was resuspended in $1 \mathrm{~mL} \mathrm{M} 2$ solution. The resuspended cells

908 were transferred into a $2-\mathrm{mL}$ microcentrifuge tube and centrifuged at $5200 \mathrm{x} \mathrm{g}$ for 5 minutes. All

909 but $\sim 250 \mu \mathrm{L}$ of supernatant was removed, $650 \mu \mathrm{L}$ M2 was added and the pellet was resuspended.

$910900 \mu \mathrm{L}$ cold Percoll (Sigma Aldrich) was added and the sample was centrifuged at 15,000 x g for

91120 minutes. Samples were taken from the bottom of the tube to select swarmer cells. 
913 Cells of Flavobacterium johnsoniae strain CJ2618 (a wild-type strain overexpressing FtsZ, ATCC

914 17061) were taken from a glycerol stock, streaked onto a CYE plate with $10 \mathrm{ug} / \mathrm{mL}$ tetracycline

915 and grown at $25^{\circ} \mathrm{C}$. Subsequently, $5 \mathrm{~mL}$ of motility medium (MM) was inoculated with colonies

916 from the plate and the culture was incubated at $25^{\circ} \mathrm{C}$ with $80 \mathrm{rpm}$ shaking overnight. Then another

$9175 \mathrm{~mL}$ MM was inoculated with $80 \mathrm{uL}$ of starter culture and placed at $25^{\circ} \mathrm{C}$ with no shaking until

918 the next day when the cells were harvested and prepared for plunge-freezing.

919

920 Helicobacter pylori mutants ( $\Delta$ fliM fliP*, $\Delta$ fliO fliP*, $P^{*}$ flgS fliP*, $\Delta$ fliG fliP*, $\Delta$ fliQ $\left.f l i P^{*}\right)$ were

921 grown from glycerol stocks on sheep blood agar at $37^{\circ} \mathrm{C}$ with $5 \% \mathrm{CO}_{2}$ for 48 hours and then either

922 plunge-frozen directly or the cells were spread on another plate and left to grow for 24 hours before

923 plunge-freezing. No difference could be discerned between the two samples by cryo-ET.

925 Flavobacterium anhuiense (strain 98, see reference [53]) and Chitinophaga pinensis (strain 94, 926 see reference [53]) cells were grown overnight in $1 / 10 \mathrm{TSB}$ at $25^{\circ} \mathrm{C}$ and $300 \mathrm{rpm}$ shaking in $50 \mathrm{ml}$

927 cultures. For sample preparation, cells were first concentrated by centrifugation. $3 \mu \mathrm{L}$ aliquots of 928 the cell suspension were applied to glow-discharged R2/2 200 mesh copper Quantifoil grids 929 (Quantifoil Micro Tools), the sample was pre-blotted for 30 seconds, and then blotted for 2.5 930 seconds (Flavobacterium anhuiense) and 1 second (Chitinophaga pinensis). Grids were pre931 blotted and blotted at $20{ }^{\circ} \mathrm{C}$ and at $95 \%$ humidity. Subsequently, the grids were plunge-frozen in 932 liquid ethane using an automated Leica EM GP system (Leica Microsystems) and stored in liquid 933 nitrogen. 


\section{Purification of Shewanella oneidensis OMVs}

937 S. oneidensis OMVs were purified as described in reference [50]. First, S. oneidensis were grown

938 in LB media until they reached $\mathrm{OD}_{600}$ of 3 . Subsequently, the cells were centrifuged at $5000 \times \mathrm{g}$

939 for 20 minutes at $4^{\circ} \mathrm{C}$; the pellet contained whole cells while the supernatant contained the OMVs.

940 To remove any cells present in the supernatant, it was filtered through a $0.45 \mu \mathrm{m}$ filter.

941 Subsequently, the supernatant was centrifuged at $38,400 \mathrm{x} g$ for one hour at $4^{\circ} \mathrm{C}$; the $\mathrm{OMVs}$ were

942 in the resultant pellet. The pellet was resuspended in $20 \mathrm{ml}$ of $50 \mathrm{mM}$ HEPES pH 6.8 buffer,

943 filtered through a $0.22 \mu \mathrm{m}$ filter, spun again as described above and ultimately resuspended in 50 944 mM HEPES pH 6.8.

946 Cryo-ET sample preparation and imaging

947 For cellular samples, $10 \mathrm{~nm}$ gold beads were first coated with BSA (bovine serum albumin) and

948 then mixed with the cells. Subsequently, $4 \mu 1$ of this mixture was applied to a glow-discharged, 949 thick carbon-coated, R2/2, 200 mesh copper Quantifoil grid (Quantifoil Micro Tools) in an FEI 950 Vitrobot chamber with 100\% humidity. Excess fluid was blotted away with filter paper and the 951 grid was plunge-frozen in a mixture of ethane/propane. For the purified OMVs of S. oneidensis,

952 the sample was first diluted to a $0.4 \mathrm{mg} / \mathrm{ml}$ concentration before it was applied to the grid [50].

953 Cryo-ET imaging of the samples was done either on an FEI Polara 300-keV field emission gun 954 transmission electron microscope equipped with a Gatan imaging filter and a K2 Summit direct 955 electron detector in counting mode, or a Thermo Fisher Titan Krios 300-keV field emission gun 956 transmission electron microscope equipped with a Gatan imaging filter and a K2 Summit counting 957 electron detector. For data collection, either the UCSF Tomography [54] or SerialEM [55] software 958 was used. For OMVs, tilt-series spanned $-60^{\circ}$ to $60^{\circ}$ with an increment of $3^{\circ}$, an underfocus of 1 - 
$9595 \mu \mathrm{m}$, and a cumulative electron dose of $121 \mathrm{e} / \AA^{2}$. For $F$. johnsoniae, tilt-series spanned $-55^{\circ}$ to

$96055^{\circ}$ with $1^{\circ}$ increment, an underfocus of $4 \mu \mathrm{m}$, a cumulative electron dose of $100 \mathrm{e} / \AA^{2}$, and a 3.9

961 Å pixel size. For M. xanthus, tilt-series spanned $-60^{\circ}$ to $60^{\circ}$ with an increment of $1^{\circ}$, an underfocus

962 of $6 \mu \mathrm{m}$, and a cumulative electron dose of $180 \mathrm{e} / \AA^{2}$. For B. burgdorferi, tilt-series spanned $-60^{\circ}$

963 to $60^{\circ}$ with $1^{\circ}$ increment, an underfocus of $10 \mu \mathrm{m}$, and a cumulative electron dose of $160 \mathrm{e} / \AA^{2}$. For

$964 H$. hepaticus, tilt-series spanned $-60^{\circ}$ to $60^{\circ}$ with increments of $1^{\circ}$, an underfocus of $12 \mu \mathrm{m}$, and a

965 cumulative electron dose of $165 \mathrm{e} / \AA^{2}$.

967 Flavobacterium anhuiense and Chitinophaga pinensis images were recorded with a Gatan K3

968 Summit direct electron detector equipped with a Gatan GIF Quantum energy filter with a slit width

969 of $20 \mathrm{eV}$. Images were taken at magnification corresponding to a pixel size of $3.28 \AA$

970 (Chitinophaga pinensis) and $4.4 \AA$ (Flavobacterium anhuiense). Tilt series were collected using

971 SerialEM with a bidirectional dose-symmetric tilt scheme $\left(-60^{\circ}\right.$ to $60^{\circ}$, starting from $\left.0^{\circ}\right)$ with a $2^{\circ}$

972 increment. The defocus was set to $-8-10 \mu \mathrm{m}$ and the cumulative exposure per tilt series was 100

$973 \mathrm{e}-/ \mathrm{A}^{2}$. Images were reconstructed with the IMOD software package.

\section{Image processing and subtomogram averaging}

976 Reconstruction of tomograms of cellular samples was done using the automatic RAPTOR pipeline

977 implemented in the Jensen laboratory at Caltech [31]. Tomograms of purified S. oneidensis OMVs

978 were reconstructed using a combination of ctffind4 [56] and the IMOD software package [57].

979 Subtomogram averaging was done using the PEET program [58], with 2-fold symmetry applied 980 along the particle $y$-axis. 
bioRxiv preprint doi: https://doi.org/10.1101/2021.07.13.452161; this version posted July 13, 2021. The copyright holder for this preprint (which was not certified by peer review) is the author/funder, who has granted bioRxiv a license to display the preprint in perpetuity. It is made available under aCC-BY 4.0 International license.

982 Table S1: A summary of the species included in this study and the major membrane structures 983 identified in each species.

\begin{tabular}{|c|c|c|c|c|c|c|c|c|c|}
\hline \multirow[t]{3}{*}{ Species } & \multirow[t]{3}{*}{ Class } & \multicolumn{8}{|c|}{ Features Observed } \\
\hline & & \multicolumn{4}{|c|}{ Tubes } & \multicolumn{2}{|c|}{ Vesicle chains } & \multirow[t]{2}{*}{$\begin{array}{l}\text { Budding/ } \\
\text { vesicles }\end{array}$} & \multirow[t]{2}{*}{ Nanopods } \\
\hline & & $\begin{array}{c}\text { Uniform } \\
\text { diameter } \\
- \\
\text { scaffold }\end{array}$ & $\begin{array}{c}\text { Uniform } \\
\text { diameter } \\
- \text { no } \\
\text { scaffold }\end{array}$ & $\begin{array}{l}\text { Variable } \\
\text { diameter }\end{array}$ & Pearling & Connectors & $\begin{array}{c}\text { No } \\
\text { connectors }\end{array}$ & & \\
\hline $\begin{array}{l}\text { Shewanella } \\
\text { oneidensis }\end{array}$ & Gammaproteobacteria & & & & & & see Ref [6] & $>100$ & \\
\hline $\begin{array}{l}\text { Pseudoalteromonas } \\
\text { luteoviolacea }\end{array}$ & Gammaproteobacteria & & $\sim 100$ & & $\sim 10$ & & & & \\
\hline $\begin{array}{l}\text { Hylemonella } \\
\text { gracilis }\end{array}$ & Betaproteobacteria & & & 3 & 4 & & & 15 & \\
\hline Delftia acidovorans & Betaproteobacteria & & & & & & & & $\begin{array}{l}\text { see Ref } \\
{[25]}\end{array}$ \\
\hline $\begin{array}{l}\text { Magnetospirillum } \\
\text { magneticum }\end{array}$ & Alphaproteobacteria & & & & & & & 49 & \\
\hline $\begin{array}{l}\text { Caulobacter } \\
\text { crescentus }\end{array}$ & Alphaproteobacteria & & & & & & & & 53 \\
\hline $\begin{array}{l}\text { Helicobacter } \\
\text { hepaticus }\end{array}$ & Epsilonproteobacteria & & & & 2 & & & & \\
\hline Helicobacter pylori & Epsilonproteobacteria & $>100$ & & & & & & & \\
\hline Myxососcus xanthus & Deltaproteobacteria & & $>100$ & & $>100$ & & & $>100$ & \\
\hline Borrelia burgdorferi & Spirochaetes & & 9 & & & 19 & & 16 & \\
\hline $\begin{array}{l}\text { Flavobacterium } \\
\text { johnsoniae }\end{array}$ & Flavobacteria & & $\sim 45$ & & $\sim 15$ & & & $>100$ & \\
\hline $\begin{array}{c}\text { Flavobacterium } \\
\text { anhuiense }\end{array}$ & Flavobacteria & & & 5 & 7 & & 4 & $\begin{array}{c}>100 \\
\text { (including } \\
\text { the } \\
\text { teardrop- } \\
\text { like } \\
\text { extensions) }\end{array}$ & \\
\hline $\begin{array}{l}\text { Chitinophaga } \\
\text { pinensis }\end{array}$ & Chitinophagia & & & 11 & 12 & & 3 & $\begin{array}{c}81 \\
\text { (including } \\
\text { the } \\
\text { teardrop- } \\
\text { like } \\
\text { extensions) }\end{array}$ & \\
\hline
\end{tabular}




\section{Acknowledgements:}

986 This project was funded by the NIH (grant R35 GM122588 to G.J.J) and a Baxter postdoctoral

987 fellowship from Caltech to M.K. Cryo-ET work was done in the Beckman Institute Resource

988 Center for Transmission Electron Microscopy at the California Institute of Technology. We are

989 grateful to Prof. Martin Pilhofer for collecting the P. luteoviolacea data and for critically reading

990 the manuscript. We thank Prof. Elitza I Tocheva for collecting the D. acidovorans data. We thank

991 Prof. Mohamed El-Naggar for insights into preparing S. oneidensis samples and Dr. Yuxi Liu for

992 discussions. Briegel lab data was collected at the Netherlands Center for Electron Nanoscopy with

993 support from Dr. Wen Yang. This data was collected with support from the National Roadmap for

994 Large-Scale Research Infrastructure 2017 - 2018 with project number 184.034.014, which is

995 financed in part by the Dutch Research Council (NWO). This work was also supported by the

996 NWO OCENW.GROOT.2019.063 grant. 